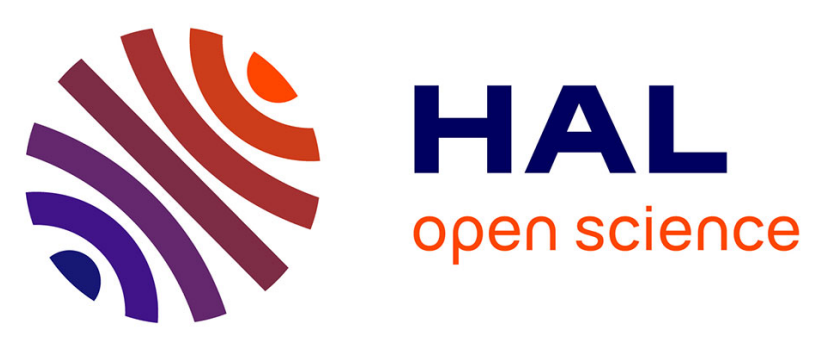

\title{
Analysis of Mycobacterium tuberculosis genetic lineages circulating in Riga and Riga region, Latvia, isolated between 2008 and 2012
}

Ilva Pole, Julija Trofimova, Inga Norvaisa, Philip Supply, Girts Skenders, Anda Nodieva, Iveta Ozere, Vija Riekstina, Viktorija Igumnova, Jelena

Storozenko, et al.

\section{To cite this version:}

Ilva Pole, Julija Trofimova, Inga Norvaisa, Philip Supply, Girts Skenders, et al.. Analysis of Mycobacterium tuberculosis genetic lineages circulating in Riga and Riga region, Latvia, isolated between 2008 and 2012. Infection, Genetics and Evolution, 2020, 78, pp.104126. 10.1016/j.meegid.2019.104126 . hal-03054014

\section{HAL Id: hal-03054014 https://hal.science/hal-03054014}

Submitted on 11 Dec 2020

HAL is a multi-disciplinary open access archive for the deposit and dissemination of scientific research documents, whether they are published or not. The documents may come from teaching and research institutions in France or abroad, or from public or private research centers.
L'archive ouverte pluridisciplinaire HAL, est destinée au dépôt et à la diffusion de documents scientifiques de niveau recherche, publiés ou non, émanant des établissements d'enseignement et de recherche français ou étrangers, des laboratoires publics ou privés.

\section{(ㅇ)(1) $\$$}

Distributed under a Creative Commons Attribution - NonCommercial - NoDerivatives 44.0 
Genetics and Evolution

Elsevier Editorial system(tm) for Infection,

Manuscript Draft

Manuscript Number: MEEGID-D-19-00518R2

Title: Analysis of Mycobacterium tuberculosis genetic lineages circulating in Riga and Riga region, Latvia, isolated between 2008 and 2012 .

Article Type: VSI: St. Petersburg Symposium

Keywords: Molecular epidemiology; genotyping; tuberculosis; drug resistance; Latvia

Corresponding Author: Dr. Renate Ranka, Ph.D.

Corresponding Author's Institution: Latvian Biomedical Research and Study Centre

First Author: Ilva Pole

Order of Authors: Ilva Pole; Jūlija Trofimova; Inga Norvaisa; Philip Supply; Girts Skenders; Anda Nodieva; Iveta Ozere; Vija Riekstina; Viktorija Igumnova; Jelena Storozenko; Inta Jansone; Ludmila Viksna; Renate Ranka, Ph.D.

Abstract: Although the number of new tuberculosis (TB) cases registered per year has decreased by 3-fold between 2001 and 2017 in Latvia, the TB incidence and rates of multidrug resistant $\mathrm{TB}$ in this Baltic country remain substantially higher than in most other European countries. Molecular typing methods of Mycobacterium tuberculosis (MTB) play an important role both in clinical studies of the disease and the epidemiological investigations, allowing to describe and characterize the pathogen's population structure and spread of particular genotypes. Aim of this study was to examine the prevalence of MTB lineages in Riga and Riga region of Latvia within a five-year period (2008 - 2012), and to evaluate the discriminatory power (DP) of spoligotyping, standard 24locus MIRU-VNTR and IS6110-RFLP methods in this setting.

The results showed that the main MTB spoligotype families were Beijing (25.3\%) and LAM (24.3\%), followed by T (22.1\%), Ural (11.2\%), Haarlem (6.6\%) and X superfamily (3.4\%). This distribution remained stable over the five consecutive years. 67.6\% of MTB isolates were pan-susceptible, and $32.4 \%$ were resistant to any drug; multi-drug resistance was found in 5.8\% of MTB strains, and 7.6\% of MTB isolates were extensively drugresistant. Drug resistance was associated with SIT1, SIT283 and SIT42 genotypes, while SIT1 and SIT42 were overrepresented among multi drugresistant MTB strains. Overall, DP of spoligotyping method alone was 0.8953, while DP of both 24-locus MIRU-VNTR analysis and IS6110 RFLP was higher ( $\mathrm{DP}=0.9846$ and 0.9927 , respectively), mainly due to the improvement of the resolution for the Beijing strains. In conclusion, this work represents the first comprehensive molecular epidemiological description of TB in Latvia, highlighting the high genetic diversity of MTB strains circulating in Riga and Riga region. In combination with detailed epidemiological data this approach was helpful for the in-depth understanding of epidemiological processes in settings where the Next-Gen sequencing is not available as a routine method. 

June 21, 2019

Editor-in-Chief

Michel Tibayrenc

Journal of Molecular Epidemiology and Evolutionary Genetics of Infectious Diseases (MEEGID)

Enclosed, please find our manuscript entitled „Analysis of Mycobacterium tuberculosis genetic lineages circulating in Riga and Riga region, Latvia, isolated between 2008 and 2012”.

This article is submitted to the Special issue on St. Petersburg Symposium on TB \& Mycobacteria (Edited by Igor Mokrousov).

It was preliminarily discussed with Dr Igor Mokrousov who encouraged this submission and thus may serve as its handling editor.

Tuberculosis is one of the major infectious diseases in Latvia, a country in the Baltic region of the northeastern Europe. Molecular genotyping methods of Mycobacterium tuberculosis play an important role both in clinical studies of the disease and in the epidemiological investigations, allowing to describe and characterize pathogen`s population structure. The aim of this study was to examine the prevalence of $M$. tuberculosis lineages in Riga and Riga region of Latvia within the five year period $(2008-2012)$, and to evaluate the discrimination power of spoligotyping, MIRU-VNTR and IS6110-RFLP methods for genotyping of $\mathrm{M}$. tuberulosis clinical isolates in this setting.

This report for the first time describes the molecular epidemiology of tuberculosis in Latvia.

The corresponding author of the manuscript, Renate Ranka, is a senior researcher in Latvian Biomedical Research and Study Centre.

I certify that this manuscript, or any part of it, has not been published and will not be submitted elsewhere for publication while being considered by the MEEGID.

No competing interests are present.

Sincerely yours,

Corresponding author:

Renate Ranka

Latvian Biomedical Research and Study Centre,

Ratsupites street 1, Riga, Latvia, LV1067.

e-mail: renate_r@biomed.lu.lv 
Response to Reviewers.

We thank the Editor and the reviewers for constructive comments that we feel substantially improved the manuscript. We have done our best to change the manuscript according to the recommendations.

Please note, that the numbering of tables and supplementary tables was changed as new data were added to the manuscript.

\section{Reviewers' comments:}

Reviewer \#1: Very good and sound paper. There will be one of the significant epidemiological works, with an excellent sampling.

My comments are below.

1. It is a pity that there is no information on drug sensitivity, although this would undoubtedly strengthen the article and shed light on the epidemiological significance of the identified genotypes (spoligotypes, clusters, RFLP types).

Moreover, the introduction gives such a characteristic: "Latvia is among the multidrug-resistant tuberculosis (MDR-TB) middle burden countries in the world: there were 36 (7.5\%) notified. MDR TB cases in 2017 (data from The Center for Disease Prevention and Control of Latvia)."

and the discussion mentions the association of the Beijing genotype with resistance, including reference to earlier studies in Latvia ("In 281 Latvia, too, Beijing genotype was prevalent among MDR-TB patients (Tracevska et al., 2003)."

Thus a comparison would allow to find out what proportion in this study are MDR strains, of which genotypes, clusters, and dynamics can be traced from 2008 to 2012.

\section{Our response.}

The information on drug resistance for the studied isolates was added (Table 4).

Sections of the manuscript (Abstract, Materials and Methods, Results, Discussion) were changed accordingly.

2. The article does not discuss clusters $94-32$ and 100-32 at all. It is interesting if there are any changes in their proportions over the years.

\section{Our response.}

The information in Discussion section was added. 
However, it was not possible to track the changes of the proportions of these MIRU-VNTR clusters over the years, as this analysis was not performed for all MTB isolates (please see also the answer below).

3. It would also be interesting to know about SIT262 (that "was associated with imprisonment"): how similar were VNTR profiles and DST profiles? Also, take note of recent paper of Sinkov et al. BMC Genomics 2018 about different association with DR of the Ural spoligotypes.

\section{Our response.}

Again, unfortunately, MIRU-VNTR was not available for all samples. The obtained data showed that MIRU/VNTR clustering rate for Ural family was not high (17 out of 46 isolates in 5 clusters); only two clusters (4 and 3 isolates) for SIT262 (Suppl. Table 3).

The drug susceptibility testing revealed that 22 of 23 SIT262 isolates were pan-susceptible (Table 4).

The information in the Discussion section was added.

4. The above questions also concern SIT254 LAM, in particular in terms of drug resistance.

\section{Our response.}

The information was added (Table 4). The majority of samples were drug-susceptible.

5. I noticed that the studied isolates were also obtained from children ( 43 aged below 20 years, in table 1). What $\%$ of all TB-diagnosed children during this period. Any idea about family contacts? Indeed this may be a subject of a separate article.

\section{Our response:}

The information was added in the Results section.

In total, within the youngest age group 16 MTB isolates were from children; no infectious source case was identified for any of these cases. All other culture-positive pediatric cases for whom epidemiological links were identified were included in a separate study (this study is in progress).

6. It would be interesting to track the dynamics of the number of clusters (VNTR) in different genotypes. Did it change or remained stable? Or at least make a table by years of main spoligotypes, to see if the structure changed.

\section{Our response:}

The authors agree that the dynamics of VNTR clusters could be interesting to explore. Unfortunately, in this study, the VNTR analysis was not available for all isolates. Only 411 samples, which were obtained mainly in years 2009-2010, were studied to explore the DP of genotyping methods in our settings. As the distribution of these samples within the years is not uniform, the analysis of the dynamics will not be accurate.

The prevalence of main spoligotypes (overall prevalence $>1 \%$ ) by years is presented in new Supplementary Table S2. 
Highlights.

- Molecular epidemiology of tuberculosis in Latvia was described for the first time

- High diversity of M. tuberculosis strains was found

- Drug resistance of M. tuberculosis isolates was analyzed.

- Association between spoligotypes and TB patients`age was found

- Combination of genotyping methods increased the resolution of the genotypes 
4 Analysis of Mycobacterium tuberculosis genetic lineages circulating in Riga and Riga

5 region, Latvia, isolated between 2008 and 2012.

7 The running title: Molecular epidemiology of tuberculosis in Latvia.

9 Ilva Pole $^{\text {a, b }}$, Julija Trofimova ${ }^{\text {a }}$, Inga Norvaisa ${ }^{\text {a }}$, Philip Supply ${ }^{\mathrm{c}}$, Girts Skenders ${ }^{\mathrm{a}}$, Anda

10 Nodieva $^{\mathrm{d}}$, Iveta Ozere ${ }^{\mathrm{a}, \mathrm{d}}$, Vija Riekstina ${ }^{\mathrm{a}}$, Viktorija Igumnova ${ }^{\text {b, d }}$, Jelena Storozenko ${ }^{\mathrm{d}, \mathrm{e}}$, Inta

11 Jansone $^{\mathrm{b}}$, Ludmila Viksna ${ }^{\mathrm{d}, \mathrm{e}}$, Renate Ranka ${ }^{\mathrm{b}, \mathrm{d}}$

13 a - Riga East University Hospital, Centre of Tuberculosis and Lung Diseases;

14 b - Latvian Biomedical Research and Study Centre;

15 c - Univ. Lille, CNRS, Inserm, CHU Lille, Institut Pasteur de Lille, U1019 - UMR 8204 -

16 CIIL - Center for Infection and Immunity of Lille, F-59000 Lille, France;

17 d - Riga Stradiņš University;

18 e - Riga East University Hospital, Latvian Centre of Infectious Diseases.

\section{Corresponding author:}

21 Renate Ranka, PhD, Latvian Biomedical Research and Study Centre, Ratsupites Str. 1, Riga, 22 Latvia, LV-1067.Phone: 371 67808219, Fax: 371 67442407, e-mail: renate_r@biomed.lu.lv 
Although the number of new tuberculosis (TB) cases registered per year has decreased by 3-fold between 2001 and 2017 in Latvia, the TB incidence and rates of multidrug resistant TB in this

27 Baltic country remain substantially higher than in most other European countries. Molecular typing methods of Mycobacterium tuberculosis (MTB) play an important role both in clinical studies of the disease and the epidemiological investigations, allowing to describe and characterize the pathogen's population structure and spread of particular genotypes. Aim of this study was to examine the prevalence of MTB lineages in Riga and Riga region of Latvia within a

32 five-year period (2008 - 2012), and to evaluate the discriminatory power (DP) of spoligotyping, standard 24-locus MIRU-VNTR and IS6110-RFLP methods in this setting.

34 The results showed that the main MTB spoligotype families were Beijing (25.3\%) and LAM

(24.3\%), followed by T (22.1\%), Ural (11.2\%), Haarlem (6.6\%) and X superfamily (3.4\%). This distribution remained stable over the five consecutive years. 67.6\% of MTB isolates were pansusceptible, and $32.4 \%$ were resistant to any drug; multi-drug resistance was found in $5.8 \%$ of MTB strains, and 7.6\% of MTB isolates were extensively drug-resistant. Drug resistance was associated with SIT1, SIT283 and SIT42 genotypes, while SIT1 and SIT42 were overrepresented among multi drug-resistant MTB strains. Overall, DP of spoligotyping method alone was 0.8953, while DP of both 24-locus MIRU-VNTR analysis and IS6110 RFLP was higher (DP=0.9846 and 0.9927, respectively), mainly due to the improvement of the resolution for the Beijing strains. In conclusion, this work represents the first comprehensive molecular epidemiological description of TB in Latvia, highlighting the high genetic diversity of MTB strains circulating in Riga and Riga region. In combination with detailed epidemiological data this approach was 
46 helpful for the in-depth understanding of epidemiological processes in settings where the Next-

47 Gen sequencing is not available as a routine method.

48 


\section{Introduction}

The epidemiological situation of tuberculosis (TB) in Latvia, a country in the Baltic

51 region of the northeastern Europe, during the last decade has improved, with 1729 (73.5 per 100

52000 population) and 483 (24.8 per 100000 population) new cases registered in year 2001 and

532017 , respectively. However, this incidence remains substantially above the average incidence in

54 most other European countries. Furthermore, Latvia is among the multidrug-resistant tuberculosis (MDR-TB) middle burden countries in the world: there were $36(7.5 \%)$ notified MDR TB cases in 2017 (data from The Centre for Disease Prevention and Control of Latvia).

Molecular typing methods of Mycobacterium tuberculosis (MTB) isolates play an important role both in clinical studies of TB and in epidemiological investigations. The

59 description of predominant MTB lineages, diversity of strains and clustering rates is necessary for monitoring the spread of TB in a particular geographic region or epidemiological settings.

61 While several genotyping methods are available to date, all these methods have their own

62 particular advantages and disadvantages in particular settings and they differ with their sensitivity, reproducibility, resolution, and discriminatory power (DP) (Supply et al., 2000; van

64 Soolingen, 2001; Supply et al., 2001; Gori et al., 2005; Supply et al., 2006; reviewed in Merker et al., 2017). Compared to classical typing methods, whole genome sequencing (WGS) method provides the most precise and comprehensive identification and characterization of MTB strain

67 genotypes. However, several barriers for clinical adoption exists including costs and the lack of bioinformatic expertise among clinical microbiologists (Satta et al., 2018). Among the classical typing methods, restriction fragment length polymorphism analysis of IS6110 (IS6110-RFLP), which have been previously known as the first gold standard for MTB strain typing, is time71 consuming and needs good quality, purified and concentrated DNA (van Soolingen, 2001). PCR- 
72 based methods such as spoligotyping (Kamerbeek et al., 1997) and 24-locus mycobacterial

73 interspersed repetitive unit variable-number tandem repeat (MIRU-VNTR) typing (Supply et al.,

74 2006) are rapid, easily performed, and can be done with very small quantities of crude DNA

75 extracts. Because of its resolution power, generally superior compared to spoligotyping and in

76 the same range as IS6110 RFLP (Supply et al., 2006; De Beer et al., 2013), molecular clustering

77 based on the latter method has been and is still largely used as a proxy to identify recent

78 transmission of MTB strains, when WGS is not accessible.

Riga is the capital of Latvia and is also the largest city in the Baltic States. With

80 approximately one million inhabitants (year 2017), Riga city and Riga region is home to $\sim 52 \%$

81 of Latvia's population (Central Statistical Bureau of Latvia, csb.gov.lv.). The aim of this study

82 was to examine the prevalence of MTB lineages in Riga and Riga region of Latvia within the

83 five year period (2008 - 2012), and to evaluate the DP of spoligotyping, MIRU-VNTR and

84 IS6110 RFLP methods for genotyping of MTB clinical isolates in this specific setting. This is

85 the first comprehensive molecular epidemiological study of TB in Latvia.

\section{Materials and methods}

\subsection{Study Setting and Design}

90 The Center of Tuberculosis and Lung Diseases, Riga East University Hospital plays a central 91 role in TB management in the country. The Center handles all MTB isolates for the Riga and 92 Riga region, and oversees routine diagnosis, and provides phenotypic drug sensitivity testing. 
94 The source of the MTB isolates was mainly sputum or induced sputum, and occasionally other

95 biological samples such as urine, faeces, bronchial aspirates, biopsy samples, pleural effusion

96 and operation material, from TB patients living in Riga and Riga region and admitted to Center

97 of Tuberculosis and Lung Diseases, Riga East University Hospital between January 2008 and

98 December 2012. Patient diagnosis was confirmed both microscopically and by culturing on solid

99 Lowenstein-Jensen (LJ) medium for 4-6 weeks. Only one isolate from each patient at time of

100 diagnosis was included in this study.

101 Epidemiological and clinical data for this study was provided by the National TB registry of

102 Latvia.

103

104 2.3. DNA extraction and genotyping

105 Mycobacterial chromosomal DNA was isolated from mycobacterial colonies grown on

106 Lowenstein Jensen (LJ) media using Cetyltrimethyl Ammonium Bromide (CTAB) method

107 (van Soolingen et al., 1991). Spoligotyping was used to identify MTB genotype for all

108 available clinical isolates. Spoligotyping was performed using commercially available kits

109 (Isogen Life Science, Netherlands; later Ocimum Biosolutions, India) following previously

110 described standard protocol (Kamerbeek et al., 1997). Spoligotyping results were analysed

111 and compared with those in SITVIT2 MTBC database was used for discrimination of MTB

112 spoligotype families (SIT numbers and families) (Couvin D et al., 2018).

113 24-locus MIRU-VNTR typing was performed using PCR followed by capillary sequencer

114 analysis, as described in (Supply et al., 2006). The 24-allele profiles were analyzed with the

115 tools implemented in the MIRU-VNTRplus online database (Weniger et al., 2010). 
116 DNA fingerprinting with IS6110 as a probe was performed by using standardized protocols as

117 described elsewhere (van Embden et al., 1993). The BioNumerics software Version 5.3

118 (Applied Maths NV, Sint-Martens-Latern, Belgium) was used for data analysis.

$119 \quad$ 2.4. Drug susceptibility testing

120 MTB drug susceptibility testing (DST) for the 1st line (isoniazid, rifampicin, ethambutol and

121 pyrazinamide) and 2nd line drugs (streptomycin, ofloxacin, kanamycin, amikacin,

122 capreomycin, ethionamide, cycloserine; para-aminosalicylic acid) was carried out for all

123 strains using the method of absolute concentrations on the solid LJ medium and Bactec MGIT

124960 system (Becton Dickinson, Heidelberg, Germany) according to WHO recommendations

125 (WHO, 2018). The laboratory is externally quality assured according to the requirements of

126 standard LVS EN ISO:15189-2013.

$127 \quad 2.5$. Statistical analysis

128 The 2-sided Fisher's exact test was employed to determine a $P$ value (GraphPad Software, La

129 Jolla, California, USA). A $P$ value equal to or less than 0.05 was considered significant. The

130 distribution of the spoligotypes among different age groups was analyzed with principal

131 components analysis (PCA) in R using FactoMineR (Lê et al., 2008). The discriminatory

132 power of each method was calculated by the Hunter-Gaston discriminatory index (HGDI). 


\section{Results}

\subsection{Epidemiological data of TB patients}

136 From January 2008 to December 2012, 4241 new TB cases were recorded in Latvia including 1371625 TB cases (38.3 \%) in Riga and Riga region. Among these cases 7.71\% (327/4241) were 138 children (age 0 - 17 years); in Riga and Riga region the proportion of pediatric cases was $9.17 \%$ 139 (149/1625). In total, in Riga and Riga region, 1308 cases were culture-positive, and 908 MTB 140 clinical isolates were available for this study.

141 Table 1 presents an overview of the demographic and clinical characteristics of culture-positive 142 TB patients included in this study. The male/female ratio was 581/327, the median age was 42 143 (1-89 years old). The majority of patients were 21-60 years old (775 individuals, 85.3\%) and 144 were born in Latvia (813 individuals, 89.5\%). Within the youngest age group (i.e. individuals 014520 years old) 16 MTB isolates were from children. Pulmonary TB was diagnosed in 861 (94.8\%) 146 cases, while $13(1.4 \%)$ patients had extra-pulmonary TB. Both types of disease were diagnosed 147 in $33(3.6 \%)$ individuals.

\subsection{MTB isolate diversity by spoligotyping}

150 Spoligotyping analysis of 908 MTB clinical isolates revealed a total of 138 different patterns 151 (DP: 0.9034) (Supplemental Table S1).

152 Of 908 isolates, 821 isolates were divided into 51 clusters (cluster size 2-224 isolates). In total, 153846 samples (93.2\%) showed shared-types or SITs when compared to the SITVIT2 MTBC 154 database. In contrast, only 11 MTB isolates (1.2\%) belonged to known orphan spoligotypes, 155 while 51 isolates (5.6\% of all samples) corresponded to a total of 38 new spoligotyping patterns 156 that have not yet been reported (Supplemental Table S1). The spoligotyping results showed that 
157 almost equal proportions of MTB strains, Latvia, belonged to the Beijing and LAM lineages in 158 Riga and the Riga region (25.4\% and $26.5 \%$, respectively) followed by T lineage (20.3\%) (Table 159 2). Less prevalent genotypes in Riga region were Haarlem (8.5\%), Ural (7.9\%) and X 160 superfamily (2.4\%), while Central Asian and East-African Indian strains were absent. Other 161 spoligotypes accounted for 8.9\% of all MTB isolates analysed. The distribution of the MTB 162 spoligotype families within the 5 year period was further analyzed, and the results are shown in 163 Table 2. A slight fluctuation in the distribution of MTB families within different years was 164 observed, however, this difference was not statistically significant $(P>0.05)$. Similarly, 165 fluctuations in the distribution of most prevalent MTB spoligotypes (prevalence $\geq 1 \%$ ) within this 166 study period were not statistically significant (Supplemental Table S2).

167 The Beijing family was represented by four spoligotypes; SIT1 was the dominant spoligotype 168 as it was detected in $224(24.7 \%)$ of all studied clinical isolates. SIT190 was found in only 169 three samples (0.3\%), while both SIT255 and SIT265 spoligotypes were detected in 2 samples 170 each (0.2\%). By contrast, higher spoligotype diversity was observed for LAM, T, and Haarlem

171 families. The LAM family comprised 241 clinical isolates and was represented by 19

172 spoligotypes including isolates belonging to LAM-RUS spoligotypes SIT254, 264, 496, 1240

173 and 2246. Further, 184 MTB isolates that belonged to the T family showed 32 different

174 spoligotypes, while the Haarlem family consisted of 77 studied isolates and was represented 175 by 13 spoligotypes (Supplemental Table S1). Overall, spoligotypes with a prevalence greater 176 than $10 \%$ among all isolates included SIT1 (Beijing, 24.7\%), SIT254 (LAM-RUS, 11.9\%) and 177 SIT53 (T family, 11.0\%), while spoligotypes with a prevalence greater than 2\% included 178 SIT42, SIT283, SIT766, SIT262, SIT40 and SIT119; other spoligotypes with a prevalence 179 lower than $2 \%$ were represented by 280 (30.8\%) MTB isolates in total (Table 1). 


\subsection{Association between spoligotypes and TB patients`characteristics}

182 Possible associations between spoligotypes and TB patients`characteristics were analyzed by

183 PCA analysis followed by statistical evaluation. Upon PCA analysis, age-related differences

184 were interestingly revealed among spoligotype patterns. In a score plot, the spoligotype SIT1

185 as well as spoligotypes with a prevalence less than $2 \%$ in the population (collectively named

186 as others in Fig. 1) were clearly separated; on the other hand, the PCA showed very close

187 distances between SIT254, SIT53, SIT42, SIT283, SIT766, SIT262, SIT40 and SIT119 for the

188 age groups studied (Figure 1). Indeed, the prevalence of SIT1 in the individuals who were

189 older than 60 years of age was decreased, while the prevalence of rare spoligotypes in older

190 individuals was significantly increased in comparison with young (age $\leq 20$ years old) patients

$191 \quad(P=0.0374)($ Table 1$)$.

192 In contrast, the data analysis revealed no differences of the distribution of spoligotypes among 193 male and female patients. Similarly, no significant differences were observed between Latvia194 born and foreign-born individuals, and for the type of the disease (Table 1).

\subsection{Association between spoligotypes and TB risk factors}

197 Further, possible association between spoligotypes and TB risk factors was explored. In this 198 study, seven different TB risk factors were analyzed which were included in the National TB 199 registry of Latvia since year 2000: housing status, alcohol abuse, drug abuse, HIV infection, 200 imprisonment, malnutrition and reported contact with a TB patient (Table 3). The majority of 201 patients had a permanent home (92.2\%), while $70(7.7 \%)$ patients were homeless. Of the patients 202 for whom HIV status was known (99.7\%), 139 (15.3\%) individuals were HIV-positive. Alcohol 
203 abuse as a risk factor was detected for 270 (29.7\%) patients, while $115(12.7 \%)$ individuals were 204 recorded as being in prison, and 79 (8.7\%) - using drugs. Malnutrition was recorded for a half of 205 all patients $(51.1 \%)$, while less than $30 \%$ of individuals have reported the contact with TB 206 patient (27.1\%). The presence of any of these seven TB risk factors was detected in the majority 207 of patients (76.5\%). Overall, the prevalence of the main spoligotypes among individuals with 208 risk factors was similar to those observed in non-risk patients $(P>0.05)$ (Table 3). However, 209 statistically significant difference was detected in the prevalence of both SIT1 and SIT53 210 spoligotypes depending on the housing status of the patients: SIT53 was more often present in

211 the homeless persons, and SIT1 was more often present in patients with permanent home $212(P=0.0083$ and $P=0.0424$, respectively). In addition, the spoligotype SIT262 was more often 213 detected in former imprisoners $(7.0 \%$ vs $1.9 \%, P=0.005)$.

\section{3.5. Drug resistance analysis}

216 Analysis of drug resistance profiles showed that $67.6 \%$ of MTB isolates were pan-susceptible 217 ( $n=614)$ and 32.4\% were resistant to any drug $(n=294)$ (Table 4). The distribution of 218 spoligotypes among drug resistant isolates was as follows: 43.2\% SIT1 (Beijing, $\mathrm{n}=127$ ), 9.9\% 219 SIT42 (LAM family, n=29), 5.8\% SIT53 (T family, n=17), 14.6\% SIT283 (Haarlem, n=43); all 220 other spoligotypes accounted for $26.5 \%(n=78)$ of drug-resistant MTB strains. Spoligotypes with

221 a drug resistance prevalence greater than 30\% among the isolates included SIT1 (Beijing, 222 56.7\%), SIT42 (LAM, 56.9\%), SIT264 (LAM-RUS, 66.7\%), SIT283 (Haarlem, 100\%) and 223 SIT1292 (Ural, 41.7\%); statistically significant difference was reached for SIT1, SIT42 and 224 SIT283 $(P \leq 0.05$; Table 4$)$. 
225 In total, MDR and extensively-drug-resistance (XDR) was found in 5.8\% (53/908) and 7.6\%

226 (69/908) of MTB strains, respectively.

227 The analysis of the distribution of spoligotypes among MDR/XDR isolates showed a significant

228 overrepresentation of both SIT1 and SIT42 isolates: these spoligotypes accounted for $47.2 \%$ and

$229 \quad 17.0 \%$ of MDR MTB, and for $55.1 \%$ and $34.0 \%$ of XDR strains, respectively (Table 4).

\section{3.6. Analysis of MTB isolates by different genotyping approaches}

232 From 908 MTB isolates, 411 samples were available for additional IS6110 RFLP and MIRU-

233 VNTR analyses and thus were used for more in-depth genotypic characterization of MTB

234 isolates in Riga and Riga region. In total, these samples represented 25.3\% of all MTB-positive

235 cultures isolated in the 2008 - 2012 time period. Among them, 78 spoligotypes were identified.

236 The isolates belonged to the following MTB families: Beijing $(\mathrm{n}=104 ; 25.3 \%), \mathrm{T}(\mathrm{n}=91 ; 22.1 \%)$,

237 LAM $(n=100 ; 24.3 \%)$, Haarlem $(n=27 ; 6.6 \%)$, Ural $(n=46 ; 11.2 \%)$ and $X(n=14 ; 3.4 \%)$; the

238 remaining $29(7.1 \%)$ represented other families and/or unpublished SITs (Table 2). This overall

239 representation of spoligotypes for these 411 isolates was similar to that observed for the full

240 MTB dataset, indicating that this selection was quite representative of the total strain set.

241 Spoligotyping alone identified 78 genotypes, 50 of which were unique; $87.8 \%$ of isolates (361 of

242 411) formed 27 clusters with a cluster range 2-31 samples.

243 Upon 24-locus MIRU-VNTR typing, 242 different MIRU-VNTR patterns were obtained; 213

244 MTB isolates (51.8\%) were grouped into 44 clusters with 2 to 37 isolates per cluster, while the

245 remaining 198 samples showed a unique MIRU-VNTR profile (Table 5; Supplemental Table

246 3). Thus, MIRU-VNTR typing had a substantially greater $\mathrm{DP}(\mathrm{DP}=0.9846)$ in comparison with

247 spoligotyping $(\mathrm{DP}=0.8953)$. 
248 When 24 MIRU-VNTR-based cluster analysis was performed for the main MTB families 249 separately, the Beijing family isolates $(n=104)$ were divided into 45 different MIRU-VNTR 250 genotypes, forming ten clusters and 35 unique genotypes. According to the MLVA MtbC15-9 251 nomenclature implemented in the MIRU-VNTR Plus database, the 3 most common allelic 252 profiles were: (1) 94-32 (244233352644425153353823) represented by 37 isolates (35.6\%); 253 (2) 100-32 (244233352644425173353723) represented by 11 isolates (10.6\%); and (3) 170-32 254 (244243352544425153353823) represented by 5 isolates (4.8\%) (Table 5; Supplemental Table 255 3). MTB isolates of the LAM lineage $(n=100)$ were divided into 44 MIRU-VNTR genotypes 256 forming ten clusters with 2-25 members and 34 unique genotypes. The 3 most common 257 genetic profiles were following: (1) 121-52 (132244332224125153322622) represented by 25 258 isolates (25.0\%); (2) 843-52 (132254332224125153322622) represented by 15 isolates 259 (15.0\%); (3) 15664-52 (132244332224125153321622) represented by 7 isolates (7.0\%).

260 In contrast, MIRU-VNTR types within the other spoligotype families were relatively more 261 diverse/less clustered. For instance, MTB isolates of T family ( $\mathrm{n}=91)$ were divided into 61 262 MIRU-VNTR genotypes, forming 11 clusters and 50 unique genotypes. The 3 most common 263 genotypes were represented by $5(5.5 \% ; 20574-15,223114322534425153342512), 6$ (6.6\%;

$264 \quad 12677-15,224243122334225143334322)$ and 7 isolates $(7.7 \% ; 20556-15$, 265 224243122434225143335322), respectively. Likewise, the largest cluster observed among the 266 isolates part of the Haarlem spoligotype family $(n=27)$ comprised only 4 isolates $(14.8 \%$; $2673527-15,223235332434425153324732)$ ), while a second cluster included only 2 isolates 268 (7.4\%). The Ural MTB family members (N=46) formed five clusters, of which 2 were of four 269 isolates each $(163-15,235237232244425113323632$ and 16668-15, 270 215237232244425113323732); three other clusters had three isolates each. The X family 
271 members $(\mathrm{n}=14)$ have formed three clusters which had only two isolates each (Supplemental 272 Table 3).

273 Next, we applied IS6110 RFLP typing to all 411 isolates. In total, 257 different patterns were 274 obtained. 207 isolates $(50.4 \%)$ were grouped into 53 clusters, and the calculated DP for the 275 RFLP genotyping method in our dataset was as high as 0.9927 (Table 5). Importantly, in the 276 case of Beijing strains, IS6110 RFLP typing showed superior resolution of the genotypes $277(\mathrm{DP}=0.9766)$ to both spoligotyping and MIRU-VNTR typing ( $\mathrm{DP}=0.0571$ and 0.8615 , 278 respectively).

279 When all three genotyping methods were combined, only 119 MTB isolates (29.0\%) were 280 grouped into 39 clusters with 2 to 12 isolates per one cluster, while the remaining 292 samples 281 have shown a unique RFLP and/or MIRU-VNTR/spoligotype patterns (Supplemental Table 282 4). The largest cluster was composed of 12 MTB isolates belonged to SIT254 (representative 283 of LAM-RUS family). In total, the LAM lineage isolates formed 9 clusters with 2-12 isolates, 284 the Beijing genotype isolates - 9 clusters (2-8 isolates), T family - 11 clusters (2-4 isolates), 285 Ural - four clusters (2-3 isolates), and X - three clusters with 2, 3 and 4 isolates each. In 286 addition, two clusters with two isolates each were obtained for the new spoligotypes 287 (spoligotype 757777777720761 and 477777663760771$)$ (Supplemental Table 4).

\section{Discussion}

290 Although MTB genotypes were previously studied in association with drug resistance in

291 Latvia (Tracevska et al., 2003; Nodieva et al., 2010; Bauskenieks et al., 2014), this is the first 292 comprehensive report describing the molecular epidemiology of TB in Riga and Riga region, 
which is home for more than $50 \%$ of Latvia's population. The analysis of the prevalence of the main MTB spoligotypes within the five-year time frame revealed the presence of 138 spoligotypes. Among them, 38 spoligotypes representing 5.6 percent of the 908 study isolates 296 had not been previously reported to the global SITVIT database. At the other extremity, the 3 297 most common spoligotypes, namely SIT1 (Beijing family), SIT53 (T family) and SIT254

298 (LAM family) accounted altogether for approximately one-half of all MTB isolates, and 299 represented $24.7,11.0$ and $11.9 \%$ of isolates, respectively. These patterns are also among the most common SITs in the world (Demay et al., 2012). In addition to be dominant in East Asia, 301 strains with the canonical Beijing SIT1 spoligotype are present in all seven geographic areas 302 of the world (Merker et al, 2015). In Europe, Beijing isolates were previously reported to be 303 very common in the Latvia's eastern and northern neighboring countries, Russia and Estonia, 304 often in association with drug resistance (Toungoussova et al., 2002; Kruuner et al., 2001). In 305 Latvia, too, Beijing genotype was prevalent among MDR-TB patients (Tracevska et al., 2003). 306 More recent data indicated that the XDR M. tuberculosis strain population in northwestern 307 Russia is heavily dominated by Beijing genotype isolates (Vyazovaya et al., 2015). In Pskov 308 oblast, which is located in northwestern Russia on the Russian/Latvian border, the Beijing 309 genotype was the most prevalent followed by LAM, T, Haarlem, Ural, and Manu2 families 310 (Mokrousov et al., 2012).

311 In this study, in total, $32.4 \%$ of MTB isolates were resistant to any drug, and $13.4 \%$ were 312 MDR/XDR strains. Unsurprisingly, Beijing genotype was highly associated with drug 313 resistance, as $43.2 \%$ of drug-resistant isolates belonged to the spoligotype SIT1. SIT1 was also 314 the predominant genotype among MDR/XDR isolates: approximately half of all MDR and 315 XDR isolates (i.e. $47.2 \%$ and 55.1\%, respectively) belonged to this spoligotype. While SIT1 
was also the most common spoligotype in our study, the predominance of this genotype among drug-resistant isolates is not related only to the simple majority. The analysis of drug resistance profiles showed that resistance to any drug and MDR/XDR phenotype was observed in $56.7 \%$ and $28.1 \%$ of the SIT1 strains, respectively. Both proportions were statistically larger when compared to the proportion of drug-resistant and MDR/XDR strains among the total number of MTB isolates (i.e. 32.4\% and 13.4\%, respectively). MIRU-VNTR analysis of Beijing isolates in Latvia showed the dominance of MTB strains belonged to clusters 94-32 (35.6\% of Beijing isolates) and 100-32 (10.6\%) which were reported to be the most common cross-border molecular clusters of MDR TB in Europe (ECDC, 2016). Similarly, Beijing clusters 94-32 and 100-32 were the dominant MTB genotypes in Central Asia, and the clonal spread of resistant TB strains, particularly of the Beijing lineage, was highlighted as a root of the MDR-TB epidemic in Central Asia (Engström et al., 2019).

However, the distribution of Beijing strains was not solely responsible for the transmission of drug-resistant TB in Latvia. Less prevalent genotypes among drug-resistant isolates were SIT283 (Haarlem, 14.6\%), SIT42 (LAM, 9.9\%), SIT53 (T family, 5.8\%) and SIT264 (LAM-RUS, 2.7\%), followed by other spoligotypes with the prevalence less than $2 \%$ each. The proportion of drug-resistant isolates among SIT42, SIT264 and SIT283 samples (56.9\%, 66.7\% and 100\%, respectively), as well as the proportion of MDR/XDR isolates among SIT42 samples (52.9\%) was significantly increased. Along with Beijing strains, the combination of spoligotyping/MIRU-VNTR analysis revealed high clustering rate for LAM family in Latvia; the two most common types were 121-52 and 843-52, which accounted for $25.0 \%$ and $15.0 \%$ of LAM isolates, respectively. While SIT254 was not associated with drug resistance, as $95.4 \%$ of isolates were pan-susceptible in our study, the distribution of other 
LAM family genotypes, including SIT42 and SIT264, is of high importance. These findings indicate that the high burden of $\mathrm{TB}$ drug resistance in Latvia is at least partially related to the

341 circulation of MTB strains of specific genotypes. Thus, genotyping of MTB strains is highly

342 important to identify significant factors involved in the distribution of resistance strains which,

343 in turn, may affect TB control programs.

344 Overall, the prevalence of different genotype families in Latvia seen in this study 345 resembles those reported for the neighboring Estonia, northwestern Russia and, to a smaller 346 extent, Belarus and Ukraine (where Ural genotypes were not observed according to previous 347 reference reports) (Figure 2) (Chernyaeva et al., 2012; Mokrousov et al., 2012; Toit et al., 348 2014; Zalutskaya et al., 2013; Nikolaevskaya et al., 2016;). Relatively to these Baltic and 349 Eastern countries, the prevalence of Beijing genotypes is substantially lower in Western 350 Europe and Scandinavia, and the proportion of isolates with spoligotype patterns typical of the 351 Euro-American lineage (alias lineage 4) of MTB is archetypally much higher (Figure 2) 352 (Demay et al., 2012; Smit et al., 2013). Interestingly, among the 51 isolates with a total of 38 novel spoligotypes that were 354 discovered among circulating MTB strains in Riga region, six shared the same spoligotype 355477777663760771 , unreported in any other world place thus far. These isolates might thus 356 represent a genotype specific to Latvia. Further studies would help to explore the frequency 357 and underlying clonal/genome diversity of this spoligotype more in details.

358 Importantly as well, the distribution pattern of the most common genotypes with a 359 dominance of Beijing, LAM and T spoligotypes remained stable over the five-year study 360 period, indicating an overall unchanged prevalence and circulation of different MTB strains in 361 the country and society. Similar result was obtained for the distribution of the most common 
362 spoligotypes including drug resistance-related SIT1, SIT42 and SIT283. This stability at least

363 within this time span limits contrasts with the substantial changes in MTB strain population

364 structures observed over time in other European countries like Ireland and Germany,

365 associated with human migration and mobility (Roycroft et al., 2018; Andrés et al., 2017).

366 These results is consistent with the fact that the vast majority of TB patients in this study, i.e.

$36789.5 \%$, were local born.

368 While we did not find any associations of spoligotypes with patients`characteristics

369 such as gender, country of birth or type of the disease, our PCA results showed that the SIT1

370 spoligotype is more frequent in 21-50 year-old adults while the rare spoligotypes were more

371 frequent in elderly patients. In keeping with the notion that the majority of infected individuals

372 remain asymptomatic over most or all of their lifetime (Zumla et al. 2013), and many of the

373 TB cases in the elderly result from reactivation of a latent MTB infection acquired at much

374 younger ages (Negin et al. 2015), the association of these rare spoligotypes with older patients

375 might reflect genotypes that were more prevalent in the past but have become less abundant

376 nowadays.

377 We also found that SIT53 (T family, representing a generic spoligotype signature that

378 can be shared by different branches of the Euro-American lineage of M. tuberculosis) isolates

379 were more common in homeless patients, while SIT1 spoligotype (Beijing family) was

380 significantly more frequent in patients with permanent home than in homeless persons, and

381 SIT262 (Ural family) was associated with imprisonment. Prisons are settings in which TB

382 transmission occurs and the incidence of TB in prisons is typically several fold higher

383 compared to the general population (reviewed in Biadglegne et al., 2015). Ural family strains

384 have not previously been associated with increased transmissibility (Mokrousov, 2012). 
385 However, additional environmental, social, and host related risk factors (like history of

386 previous imprisonment in other (Eastern) countries, of contacts with prisoners with such a

387 history) could facilitate the spread of particular TB strains in these places (Biadglegne et al.,

388 2015). Similarly, low socioeconomic status and enhanced exposure in crowded places such as

389 homeless shelters may have an impact on the transmission dynamics of particular strains (part

390 of the Euro-American lineage in this case) in specific patient groups, such as homeless people.

391 Also, recent report of Sinkov and colleagues highlighted the recent emergency of Ural Clade C

392 (belongs to SIT262) in Eastern European countries Moldova and Belarus which was

393 significantly associated with XDR or pre-XDR status (Sinkov et al., 2019). In our study, the

394 majority of SIT262 isolates were pan-susceptible (22 of 23), while drug resistant strains

395 including those with MDR phenotype were found among isolates belonging to other Ural

396 family spoligotypes SIT35, 1292 and 3344. These findings demonstrated the circulation of

397 Ural strains with concern for drug resistance and the need for detection and surveillance of

398 these strains in Eurasia to prevent further dissemination.

Consistently with multiple previous studies, our results show that, although it is a rapid

400 and convenient genotyping method for broad identification of genotype families in clinical

401 strains (Gori et al., 2005) (Millet et al., 2007), spoligotyping cannot be used alone in order to

402 investigate the possible epidemiological links between patients, especially in settings

403 dominated by the Beijing lineage. Isolates with Beijing spoligotypes were the most common in

404 our study, resulting in a spoligotyping clustering rate of 97.1\% (101/104 isolates) and a

405 calculated DP for as low as 0.057 for these isolates. Unsurprisingly as well, the 24-locus

406 MIRU-VNTR analysis clearly increased the overall resolution of the obtained MTB genotypes

407 (calculated DP=0.9846), and especially among isolates with a Beijing spoligotype with a 
resulting clustering rate of $66.4 \%$ (69/104) among them. Likewise, IS6110 RFLP typing had a much higher resolution in comparison with spoligotyping ( $\mathrm{DP}=0.9927)$, and in the case of Beijing lineage the DP was the highest among the methods applied (DP=0.9766). Given that

411 spoligotyping is both an appropriate routine method for a clinical laboratory in Latvia and a

412 useful screen to identify geneotype families, a combination of this method with at least one of

413 the two other molecular genotyping approaches should be used in order to correctly interpret 414 typing results for the needs in epidemiological tracing.

In conclusions, we report the first comprehensive molecular epidemiological study of TB

417 in Latvia. This study highlighted the high genetic diversity of $M$. tuberculosis strains circulating 418 in Riga and Riga region. The combination of the spoligotyping with the 24-locus MIRU-VNTR 419 and IS6110 RFLP clearly increased the overall resolution of the MTB genotypes. In combination 420 with detailed epidemiological data, this approach was helpful for a first in-depth understanding 421 of epidemiological processes in a settings where the Next-Gen sequencing is not available as a 422 routine method.

\section{Acknowledgments}

426 This study was supported by the EU 7th Framework TB - PANNET and Latvian National

427 Research program VPP-2010-1/9.3 and VPP "BIOMEDICINE". P.S. was a consultant for 428 Genoscreen. 


\section{References}

432 1. Andrés, M., Göhring-Zwacka, E., Fiebig, L., Priwitzer, M., Richter, E., Rüsch-Gerdes, S., Haas, W., Niemann, S., Brodhun, B., 2017. Integration of molecular typing results into tuberculosis surveillance in Germany-A pilot study. PLoS One. 12(11):e0188356. doi: 10.1371/journal.pone.0188356.

2. Bauskenieks, M., Pole, I., Skenders, G., Jansone, I., Broka, L., Nodieva, A., Ozere, I., Kalvisa, A., Ranka, R., Baumanis, V., 2015. Genotypic and phenotypic characteristics of aminoglycoside-resistant Mycobacterium tuberculosis isolates in Latvia. Diagn. Microbiol. Infect. Dis.81(3):177-82. doi: 10.1016/j.diagmicrobio.2014.12.004. 900. doi: 10.1017/S095026881400288X. resistance of tuberculosis in prisons: a hidden epidemic. Epidemiol. Infect. 143(5):887-

4. Brudey, K., Gordon, M., Moström, P., Svensson, L., Jonsson, B., Sola, C., Ridell, M., Rastogi, N., 2004. Molecular epidemiology of Mycobacterium tuberculosis in western Sweden. J. Clin. Microbiol. 42(7):3046-51.

5. Chernyaeva, E., Dobrynin, P., Pestova, N., Matveeva, N., Zhemkov, V., Kozlov, A., 2012. Molecular genetic analysis of Mycobacterium tuberculosis strains spread in different patient groups in St. Petersburg, Russia. Eur. J. Clin. Microbiol. Infect. Dis. 31(8):1753-7. doi: 10.1007/s10096-011-1497-2.

6. Couvin, D., David, A., Zozio, T., Rastogi, N., 2018. Macro-geographical specificities of the prevailing tuberculosis epidemic as seen through SITVIT2, an updated version of the Mycobacterium tuberculosis genotyping database. Infect Genet Evol. S15671348(18)30969-9. doi: 10.1016/j.meegid.2018.12.030. 
7. De Beer, J.L., van Ingen, J., de Vries, G., Erkens, C., Sebek, M., Mulder, A., Sloot, R., van den Brandt, A.M., Enaimi, M., Kremer, K., Supply, P., van Soolingen D., 2013. Comparative study of IS6110 RFLP and VNTR typing of Mycobacterium tuberculosis in the Netherlands, based on a five year nationwide survey. J. Clin. Microbiol. 51(4):11938. doi: 10.1128/JCM.03061-12.

8. Demay, C., Liens, B., Burguière, T., Hill, V., Couvin, D., Millet, J., Mokrousov, I., Sola, C., Zozio, T., Rastogi, N., 2012. SITVITWEB-a publicly available international multimarker database for studying Mycobacterium tuberculosis genetic diversity and molecular epidemiology. Infect. Genet. Evol. 12(4):755-66. doi: 10.1016/j.meegid.2012.02.004.

9. Engström, A., Antonenka, U., Kadyrov, A., Kalmambetova, G., Kranzer, K., Merker, M., Kabirov, O., Parpieva, N., Rajabov, A., Sahalchyk, E., Sayfudtinov, Z., Niemann, S., Hoffmann, H., 2019. Population structure of drug-resistant Mycobacterium tuberculosis in Central Asia. BMC Infect Dis. 29;19(1):908.

10. European Centre for Disease Prevention and Control. Molecular typing for surveillance of multidrug-resistant tuberculosis in the EU/EEA - January 2016. Stockholm: ECDC; 2016.

11. Gori, A., Bandera, A., Marchetti, G., Degli Esposti, A., Catozzi, L., Nardi, G.P., Gazzola, L., Ferrario, G., van Embden, J.D., van Soolingen, D., Moroni, M., Franzetti, F., 2005. Spoligotyping and Mycobacterium tuberculosis. Emerg Infect Dis. 11(8):1242-8.

12. Kamerbeek, J., Schouls, L., Kolk, A., van Agterveld, M., van Soolingen, D., et al., 1997. Simultaneous detection and strain differentiation of Mycobacterium tuberculosis for diagnosis and epidemiology. J. Clin. Microbiol. 35: 907-914. 
13. Kruuner, A., S. E. Hoffner, H. Sillastu, M. Danilovits, K. Levina, S. B. Svenson, S. Ghebremichael, T. Koivula, and G. Kallenius. 2001. Spread of drug-resistant pulmonary tuberculosis in Estonia. J. Clin. Microbiol. 39: 3339-3345.

14. Lê, S., Josse, J., Husson, F., 2008. FactoMineR: An R Package for Multivariate Analysis. Journal of Statistical Software. 25(1):1-18.

15. Merker, M., Blin, C., Mona, S., Duforet-Frebourg, N., Lecher, S., Willery, E., Blum, M.G., Rüsch-Gerdes, S., Mokrousov, I., Aleksic, E., Allix-Béguec, C., Antierens, A., Augustynowicz-Kopeć, E., Ballif, M., Barletta, F., Beck, H.P., Barry, C.E., Bonnet, M., Borroni, E., Campos-Herrero, I., Cirillo, D., Cox, H., Crowe, S., Crudu, V., Diel, R., Drobniewski, F., Fauville-Dufaux, M., Gagneux, S., Ghebremichael, S., Hanekom, M., Hoffner, S., Jiao, W.W., Kalon, S., Kohl, T.A., Kontsevaya, I., Lillebæk, T., Maeda, S., Nikolayevskyy, V., Rasmussen, M., Rastogi, N., Samper, S., Sanchez-Padilla, E., Savic, B., Shamputa, I.C., Shen, A., Sng, L.H., Stakenas, P., Toit, K., Varaine, F., Vukovic, D., Wahl, C., Warren, R., Supply, P., Niemann, S., Wirth, T., 2015. Evolutionary history and global spread of the Mycobacterium tuberculosis Beijing lineage. Nat. Genet. 47(3):2429. doi: 10.1038/ng.3195.

16. Merker, M., Kohl, T.A., Niemann, S., Supply, P., 2017. The Evolution of Strain Typing in the Mycobacterium tuberculosis complex. Adv. Exp. Med. Biol. 1019:43-78. doi: 10.1007/978-3-319-64371-7_3.

17. Millet, J., Miyagi-Shiohira, C., Yamane, N., Sola, C., Rastogi, N., 2007. Assessment of mycobacterial interspersed repetitive unit-QUB markers to further discriminate the Beijing genotype in a population-based study of the genetic diversity of Mycobacterium 
tuberculosis clinical isolates from Okinawa, Ryukyu Islands, Japan. J. Clin. Microbiol.

500

501

502

503

504

505

506

507

508

509

510 45(11):3606-15.

18. Mokrousov, I., 2012. The quiet and controversial: Ural family of Mycobacterium tuberculosis. Infect. Genet. Evol. 12(4):619-29. doi: 10.1016/j.meegid.2011.09.026.

19. Mokrousov, I., Vyazovaya, A., Otten, T., Zhuravlev, V., Pavlova, E., Tarashkevich, L., Krishevich, V., Vishnevsky, B., Narvskaya, O., 2012. Mycobacterium tuberculosis population in northwestern Russia: an update from Russian-EU/Latvian border region. PLoS One. 7(7):e41318.

20. Mokrousov, I., Vyazovaya, A., Solovieva, N., Sunchalina, T., Markelov, Y., Chernyaeva, E., Melnikova, N., Dogonadze, M., Starkova, D., Vasilieva, N., Gerasimova, A., Kononenko, Y., Zhuravlev, V., Narvskaya, O., 2015. Trends in molecular epidemiology of drug-resistant tuberculosis in Republic of Karelia, Russian Federation. BMC Microbiol. 15:279. doi: 10.1186/s12866-015-0613-3.

21. Negin, J., Abimbola, S., Marais, B.J., 2015. Tuberculosis among older adults--time to take notice. Int. J. Infect. Dis. 32():135-7.

22. Nikolaevskaya, E., Pavlovska, O., Molina, B., Brännberg, P., Marynova, I., Krylova, K., Ivanitsa, T., Filuk, V., Lacoma, A., Dominguez, J., Rzhepishevska, O., Prat, C., 2016. Spoligotypes of Mycobacterium tuberculosis isolated from tuberculosis patients in Odessa, Ukraine. European Congress of Clinical Microbiology and Infectious Diseases. Amsterdam, Netherlands, 9-12 April, 2016. P0155.

23. Nodieva, A., Jansone, I., Broka, L., Pole, I., Skenders, G., Baumanis, V., 2010. Recent nosocomial transmission and genotypes of multidrug-resistant Mycobacterium tuberculosis. Int. J. Tuberc. Lung Dis. 14(4):427-33. 
24. Roycroft, E., O'Toole, R.F., Fitzgibbon, M.M., Montgomery, L., O'Meara, M., Downes, P., Jackson, S., O'Donnell, J., Laurenson, I.F., McLaughlin, A.M., Keane, J., Rogers, T.R., 2018. Molecular epidemiology of multi- and extensively-drug-resistant Mycobacterium tuberculosis in Ireland, 2001-2014. J. Infect. 76(1):55-67. doi: 10.1016/j.jinf.2017.10.002.

25. Satta, G., Lipman, M., Smith, G.P., Arnold, C., Kon, O.M., McHugh, T.D., 2018. Mycobacterium tuberculosis and whole-genome sequencing: how close are we to unleashing its full potential? Clin. Microbiol. Infect. 24(6):604-609. doi: 10.1016/j.cmi.2017.10.030.

26. Sinkov, V., Ogarkov, O., Mokrousov, I., Bukin, Y., Zhdanova, S., Heysell, S.K., 2019. New epidemic cluster of pre-extensively drug resistant isolates of Mycobacterium tuberculosis Ural family emerging in Eastern Europe. BMC Genomics. 19(1):762. doi: $10.1186 / \mathrm{s} 12864-018-5162-3$.

27. Smit, P.W., Haanperä, M., Rantala, P., Couvin, D., Lyytikäinen, O., Rastogi, N., Ruutu, P., Soini, H., 2013. Molecular Epidemiology of Tuberculosis in Finland, 2008-2011. PLoS One. 8(12): e85027.

28. Supply, P., C. Allix, S. Lesjean, M. Cardoso-Oelemann, S. Rusch-Gerdes, E. Willery, E. Savine, P. de Haas, H. van Deutekom, S. Roring, P. Bifani, N. Kurepina, B. Kreiswirth, C. Sola, N. Rastogi, V. Vatin, M. C. Gutierrez, M. Fauville, S. Niemann, R. Skuce, K. Kremer, C. Locht, and D. van Soolingen. 2006. Proposal for standardization of optimized mycobacterial interspersed repetitive unit-variable-number tandem repeat typing of Mycobacterium tuberculosis . J. Clin. Microbiol. 44:4498-4510. 
29. Supply, P., Mazars, E., Lesjean, S., Vincent, V., Gicquel, B., et al., 2000. Variable human minisatellite-like regions in the Mycobacterium tuberculosis genome. Mol. Microbiol. 36: $762-771$.

30. Supply, P., Lesjean, S., Savine, E., Kremer, K., van Soolingen, D., Locht, C., 2001. Automated high-throughput genotyping for study of global epidemiology of Mycobacterium tuberculosis based on mycobacterial inter- spersed repetitive units. J. Clin. Microbiol. 39: 3563-3571.

31. Toit, K., Altraja, A., Acosta, C.D., Viiklepp, P., Kremer, K., Kummik, T., Danilovitš, M., Van den Bergh, R., Harries, A.D., Supply, P., 2014. A four-year nationwide molecular epidemiological study in Estonia: risk factors for tuberculosis transmission. Public Health Action. 4(Suppl 2):S34-40. doi: 10.5588/pha.14.0045.

32. Toungoussova, O. S., P. Sandven, A. O. Mariandyshev, N. I. Nizovtseva, G. Bjune, and D. A. Caugant. 2002. Spread of drug-resistant Mycobacterium tuberculosis strains of the Beijing genotype in the Archangel Oblast, Russia. J. Clin. Microbiol. 40:1930-1937.

33. Tracevska, T., Jansone, I., Baumanis, V., Marga, O., Lillebaek, T., 2003. Prevalence of Beijing genotype in Latvian multidrug-resistant Mycobacterium tuberculosis isolates. Int. J. Tuberc. Lung Dis. 7(11):1097-103.

34. Vyazovaya, A., Levina, K., Zhuravlev, V., Viiklepp, P., Kütt, M., Mokrousov, I., 2018. Emerging resistant clones of Mycobacterium tuberculosis in a spatiotemporal context. J Antimicrob. Chemother. 73(2):325-331. doi: 10.1093/jac/dkx372.

35. Vyazovaya, A., Mokrousov, I., Zhuravlev, V., Solovieva, N., Otten, T., Vishnevsky, B., Narvskaya, O., 2015. Dominance of the Beijing genotype among XDR Mycobacterium tuberculosis strains in Russia. Int. J. Mycobacteriol. 4 (S1):84-85. 
36. Van Embden, J.D., Cave, M.D., Crawford, J.T., Dale, J.W., Eisenach, K.D., Gicquel, B., Hermans, P., McAdam, R., Shinnick, T.M., Small, P.M., 1993. Strain identification of Mycobacterium tuberculosis by DNA fingerprinting: recommendations for a standardized methodology. J. Clin. Microbiol. 31: 406-409.

37. Van Soolingen, D., 2001. Molecular epidemiology of tuberculosis and other mycobacterial infections: main methodologies and achievements. J. Intern. Med. 249 (1): p. 1-26.

38. van Soolingen, D., Hermans, P.W., de Haas, P.E., Soll, D.R., van Embden, J.D., 1991. Occurrence and stability of insertion sequences in Mycobacterium tuberculosis complex strains: evaluation of an insertion sequence-dependent DNA polymorphism as a tool in the epidemiology of tuberculosis. J. Clin. Microbiol. 29(11):2578-86.

39. Weniger, T., Krawczyk, J., Supply, P., Niemann, S., Harmsen, D., 2010. MIRUVNTRplus: a web tool for polyphasic genotyping of Mycobacterium tuberculosis complex bacteria. Nucleic Acids Res. 38(Web Server issue):W326-31. doi: 10.1093/nar/gkq351.

40. World Health Organization (WHO). Technical manual for drug susceptibility testing of medicines used in the treatment of tuberculosis. Geneva: World Health Organization; 2018.

41. Zalutskaya, A., Wijkander, M., Jureen, P., Skrahina, A., Hoffner, S., 2013. Multidrugresistant Myobacterium tuberculosis caused by the Beijing genotype and a specific T1 genotype clone (SIT No. 266) is widely transmitted in Minsk. Int. J. Mycobacteriol. 2(4):194-8. doi: 10.1016/j.ijmyco.2013.08.001. Epub 2013 Sep 6. 
42. Zumla, A., Raviglione, M., Hafner ,R., von Reyn, C.F., 2013. Tuberculosis. N. Engl. J.

590 Med. 368(8):745-55. doi: 10.1056/NEJMra1200894.

591

592 


\section{$593 \quad$ Figure captures}

594 Figure 1. Principal component analysis (PCA) of the M. tuberculosis spoligotypes in age groups.

595 PCA map showed remarkable segregation of SIT1 and spoligotypes with a prevalence less than

$5962 \%$ in the population (collectively named as Others).

597

598 Figure 2. Distribution of $M$. tuberculosis lineages in Latvia and neighboring countries. Data

599 were obtained: Latvia, this study; Russia, Mokrousov et al., 2015; Estonia, Vyazovaya et al.,

600 2018; Finland, Smit et al., 2013; Sweden, Brudey et al., 2004; Belarus, Zalutskaya et al., 2013;

601 Ukraine, Nikolaevskaya et al., 2016; Poland, SITWIT database; Germany, SITVIT database;

602 Denmark, SITVIT database.

603 
Table 1. Characteristics of patients in Riga and Riga region, 2008-2012 ( $n=908)$ and association between main spoligotypes.

\begin{tabular}{|c|c|c|c|c|c|c|c|c|c|c|c|c|}
\hline & & \multirow{2}{*}{$\begin{array}{l}\text { MTB } \\
\text { isolates in } \\
\text { this study } \\
\text { No. }(\%)^{*}\end{array}$} & \multicolumn{10}{|c|}{ Spoligotype, No. of strains (\%) } \\
\hline & & & $\begin{array}{l}\text { SIT1 } \\
\mathrm{N}=224 \\
(24.7) \\
\end{array}$ & $\begin{array}{l}\text { SIT254 } \\
\mathrm{N}=108 \\
(11.9)\end{array}$ & $\begin{array}{l}\text { SIT53 } \\
\mathrm{N}=100 \\
(11.0) \\
\end{array}$ & $\begin{array}{l}\text { SIT42 } \\
\mathrm{N}=51 \\
(5.6) \\
\end{array}$ & $\begin{array}{l}\text { SIT283 } \\
N=43 \\
(4.7)\end{array}$ & $\begin{array}{l}\text { SIT766 } \\
\mathrm{N}=35 \\
(3.9) \\
\end{array}$ & $\begin{array}{l}\text { SIT262 } \\
\mathrm{N}=23 \\
(2.5)\end{array}$ & $\begin{array}{l}\text { SIT40 } \\
\mathrm{N}=23 \\
(2.5) \\
\end{array}$ & $\begin{array}{l}\text { SIT119 } \\
N=21 \\
(2.3)\end{array}$ & $\begin{array}{l}\text { Others } \\
\mathrm{N}=280 \\
(30.8)\end{array}$ \\
\hline \multirow[t]{2}{*}{ Sex } & Male & $581(64.0)$ & $137(23.6)$ & $65(11.2)$ & $60(10.3)$ & $37(6.4)$ & $32(5.5)$ & $28(4.8)$ & $17(2.9)$ & $12(2.1)$ & $11(1.9)$ & $182(31.3)$ \\
\hline & Female & $327(36.0)$ & 87 (26.6) & $43(13.2)$ & $40(12.2)$ & $14(4.3)$ & $11(3.4)$ & $7(2.1)$ & $6(1.8)$ & $11(3.4)$ & $10(3.1)$ & $98(30.0)$ \\
\hline \multirow[t]{8}{*}{ Age } & $\leq 20$ & $43(4.7)$ & $13(30.2)$ & $3(7.0)$ & $6(14.0)$ & 5 (11.6) & $3(7.0)$ & - & $3(7.0)$ & - & $2(4.7)$ & 8 (18.6) \\
\hline & $21-30$ & $183(20.2)$ & $41(22.4)$ & $22(12.0)$ & $15(8.2)$ & $12(6.6)$ & $9(4.9)$ & $10(5.5)$ & $4(2.2)$ & $8(4.4)$ & $3(1.6)$ & $59(32.2)$ \\
\hline & $31-40$ & $230(25.3)$ & $56(24.3)$ & $33(14.3)$ & $23(10.0)$ & $9(3.9)$ & $11(4.8)$ & $10(4.3)$ & $8(3.5)$ & $3(1.3)$ & $7(3.0)$ & $70(30.4)$ \\
\hline & $41-50$ & $206(22.7)$ & $53(25.7)$ & $17(8.3)$ & $30(14.6)$ & $11(5.3)$ & $6(2.9)$ & $6(2.9)$ & $4(1.9)$ & $3(1.5)$ & $2(1.0)$ & $74(35.9)$ \\
\hline & $51-60$ & $156(17.2)$ & $38(24.4)$ & $15(9.6)$ & $12(7.7)$ & $8(5.1)$ & $7(4.5)$ & $6(3.9)$ & $3(1.9)$ & $6(3.9)$ & $3(1.9)$ & $58(37.2)$ \\
\hline & $61-70$ & $47(5.2)$ & $9(19.2)$ & $7(14.9)$ & $5(10.6)$ & $1(2.2)$ & $1(2.2)$ & $2(4.3)$ & - & $1(2.2)$ & $2(4.3)$ & $19(40.4)$ \\
\hline & $71-80$ & $27(3.0)$ & $4(14.8)$ & $2(7.4)$ & $1(3.7)$ & $1(3.7)$ & $2(7.4)$ & - & $1(3.7)$ & - & $1(3.7)$ & $15(55.6)$ \\
\hline & $\geq 81$ & $13(1.4)$ & - & - & $1(7.7)$ & - & $1(7.7)$ & - & - & $1(7.7)$ & - & $10(76.9)$ \\
\hline \multirow{3}{*}{$\begin{array}{l}\text { Country } \\
\text { of birth }\end{array}$} & Latvia & $813(89.5)$ & $208(25.6)$ & 97 (11.9) & $90(11.1)$ & $47(5.8)$ & $37(4.6)$ & $33(4.1)$ & $21(2.6)$ & $20(2.5)$ & $18(2.2)$ & $242(29.8)$ \\
\hline & Foreign country & $94(10.4)$ & $16(17.0)$ & $11(11.7)$ & $10(10.6)$ & $4(4.3)$ & $6(6.4)$ & $2(2.1)$ & $2(2.1)$ & $3(3.2)$ & $3(3.2)$ & $37(39.4)$ \\
\hline & Unknown & $1(0.1)$ & - & - & - & - & - & - & - & - & - & - \\
\hline \multirow{4}{*}{$\begin{array}{l}\text { Type of } \\
\text { disease }\end{array}$} & Pulmonary TB & $861(94.8)$ & $216(25.1)$ & $102(11.9)$ & $93(10.8)$ & $50(5.8)$ & $39(4.5)$ & $33(3.8)$ & $23(2.7)$ & $23(2.7)$ & $20(2.3)$ & $262(30.4)$ \\
\hline & Extra-pulmonary TB & $13(1.4)$ & $2(0.9)$ & $1(0.9)$ & - & - & $1(2.3)$ & - & - & - & $1(4.8)$ & $8(44.4)$ \\
\hline & Both types & $33(3.6)$ & $6(18.2)$ & $5(15.2)$ & $7(21.2)$ & 1 & $3(9.1)$ & $2(6.1)$ & - & - & - & $9(27.3)$ \\
\hline & Unknown & $1(0.1)$ & - & - & - & - & - & - & - & - & - & - \\
\hline
\end{tabular}


Table 2. Prevalence of MTB spoligotype families in Riga and Riga region, 2008 - 2012.

\begin{tabular}{|c|c|c|c|c|c|c|c|c|c|}
\hline \multirow[t]{2}{*}{ Year } & \multirow{2}{*}{$\begin{array}{l}\text { Registered } \\
\text { NEW TB cases } \\
\text { in Riga and } \\
\text { Riga region } \\
\text { (MTB-positive } \\
\text { cultures) }\end{array}$} & \multirow{2}{*}{$\begin{array}{l}\text { MTB } \\
\text { isolates in } \\
\text { this study } \\
\text { No. }(\%)^{*}\end{array}$} & \multicolumn{7}{|c|}{ Spoligotype family, No. of strains (\%) } \\
\hline & & & Beijing & LAM & $\mathrm{T}$ & Haarlem & Ural & $\mathrm{X}$ & Others \\
\hline 2008 & $354(288)$ & $181(62.8)$ & $41(22.7)$ & $50(27.6)$ & $38(21.0)$ & $23(12.7)$ & $9(5.0)$ & $2(1.1)$ & $18(9.9)$ \\
\hline 2009 & $305(253)$ & $212(83.8)$ & $55(25.9)$ & $42(19.8)$ & $41(19.3)$ & $14(6.6)$ & $27(12.7)$ & $9(4.3)$ & $24(11.3)$ \\
\hline 2010 & $305(245)$ & $183(74.7)$ & $40(21.9)$ & $52(28.4)$ & $37(20.2)$ & $14(7.7)$ & $17(9.3)$ & $5(2.7)$ & $18(9.8)$ \\
\hline 2011 & $315(250)$ & $180(72.0)$ & $50(27.8)$ & $54(30.0)$ & $37(20.6)$ & $16(8.9)$ & $9(5.0)$ & $4(2.2)$ & $10(5.6)$ \\
\hline 2012 & $346(272)$ & $152(56.0)$ & 45 (29.6) & $43(28.3)$ & $31(20.4)$ & $10(6.6)$ & $10(6.6)$ & $2(1.3)$ & $11(7.2)$ \\
\hline Total & $1625(1308)$ & 908 (69.4) & $231(25.4)$ & $241(26.5)$ & $184(20.3)$ & $77(8.5)$ & $72(7.9)$ & $22(2.4)$ & $81(8.9)$ \\
\hline $\begin{array}{l}\text { Set of } \\
\text { samples } * *\end{array}$ & - & $411(25.3)$ & $104(25.3)$ & $100(24.3)$ & $91(22.1)$ & $27(6.6)$ & $46(11.2)$ & $14(3.4)$ & $29(7.1)$ \\
\hline
\end{tabular}

* The proportion of the MTB-positive cultures.

** Set of MTB samples which were genotyped by all three genotyping methods (Spoligotyping, 24-loci MIRU-VNTR and IS6110 $\operatorname{RFLP}(\mathrm{n}=411)$. 
Table 3. Spoligotyping of $908 \mathrm{M}$. tuberculosis clinical samples and association between main spoligotypes and patients` risk factors.

\begin{tabular}{|c|c|c|c|c|c|c|c|c|c|c|c|c|}
\hline \multicolumn{2}{|l|}{ Risk factor } & \multirow{3}{*}{$\begin{array}{l}\text { MTB } \\
\text { isolates, } \\
\text { No. }(\%) \\
837(92.2)\end{array}$} & \multicolumn{10}{|c|}{ Spoligotype, No. of strains (\%) } \\
\hline & & & $\begin{array}{l}\text { SIT1 } \\
\mathrm{N}=224 \\
(24.7)\end{array}$ & $\begin{array}{l}\text { SIT254 } \\
\mathrm{N}=108 \\
(11.9) \\
\end{array}$ & $\begin{array}{l}\text { SIT53 } \\
\mathrm{N}=100 \\
(11.0) \\
\end{array}$ & $\begin{array}{l}\text { SIT42 } \\
\mathrm{N}=51 \\
(5.6) \\
\end{array}$ & $\begin{array}{l}\text { SIT283 } \\
\mathrm{N}=43 \\
(4.7) \\
\end{array}$ & $\begin{array}{l}\text { SIT766 } \\
\mathrm{N}=35 \\
(3.9) \\
\end{array}$ & $\begin{array}{l}\text { SIT262 } \\
\mathrm{N}=23 \\
(2.5) \\
\end{array}$ & $\begin{array}{l}\text { SIT40 } \\
\mathrm{N}=23 \\
(2.5) \\
\end{array}$ & $\begin{array}{l}\text { SIT119 } \\
\mathrm{N}=21 \\
(2.3) \\
\end{array}$ & $\begin{array}{l}\text { Others } \\
\mathrm{N}=280 \\
(30.8)\end{array}$ \\
\hline \multirow[t]{3}{*}{$\begin{array}{l}\text { Housing } \\
\text { status }\end{array}$} & $\begin{array}{l}\text { Permanent } \\
\text { home }\end{array}$ & & $214(25.6) *$ & $100(12.0)$ & $85(10.2)^{* *}$ & $48(5.7)$ & $41(4.9)$ & $31(3.7)$ & $20(2.4)$ & $21(2.5)$ & $17(2.0)$ & $260(31.1)$ \\
\hline & Homeless & $70(7.7)$ & $10(14.3)$ & $8(11.4)$ & $15(21.4)$ & $3(4.3)$ & $2(2.9)$ & $4(5.7)$ & $3(4.3)$ & $1(1.4)$ & $4(5.7)$ & $20(28.6)$ \\
\hline & Unknown & $1(0.1)$ & & & & & & & & & & \\
\hline \multirow[t]{3}{*}{ Alcohol abuse } & Yes & $270(29.7)$ & $67(24.8)$ & $24(8.9)$ & $35(13.0)$ & $13(4.8)$ & $12(4.4)$ & $11(4.1)$ & $10(3.7)$ & $6(2.2)$ & $8(3.0)$ & $84(31.1)$ \\
\hline & No & $637(70.2)$ & $157(24.7)$ & $84(13.2)$ & $65(10.2)$ & $38(6.0)$ & $31(4.9)$ & $24(3.8)$ & $13(2.0)$ & $17(2.7)$ & $13(2.0)$ & $195(30.6)$ \\
\hline & Unknown & $1(0.1)$ & & & & & & & & & & \\
\hline \multirow[t]{3}{*}{ Drug abuse } & Yes & $79(8.7)$ & $18(22.8)$ & $15(19.0)$ & $6(7.6)$ & $3(3.8)$ & $3(3.8)$ & $2(2.5)$ & $4(5.1)$ & $2(2.5)$ & $3(3.8)$ & $23(29.1)$ \\
\hline & No & $828(91.2)$ & $206(24.9)$ & $93(11.2)$ & $94(11.4)$ & $48(5.8)$ & $40(4.8)$ & $33(4.0)$ & $19(2.3)$ & $21(2.5)$ & $18(2.2)$ & $256(30.9)$ \\
\hline & Unknown & $1(0.1)$ & & & & & & & & & & \\
\hline \multirow{3}{*}{ HIV positive } & Yes & $139(15.3)$ & $38(27.3)$ & $23(16.6)$ & $10(7.2)$ & $8(5.8)$ & $8(5.8)$ & $3(2.2)$ & $5(3.6)$ & $2(1.4)$ & $5(3.6)$ & 37 (26.6) \\
\hline & No & $768(84.6)$ & $186(24.2)$ & $85(11.1)$ & $90(11.7)$ & $43(5.6)$ & $35(4.6)$ & $32(4.2)$ & $18(2.3)$ & $21(2.7)$ & $16(2.1)$ & $242(31.5)$ \\
\hline & Unknown & $1(0.1)$ & & & & & & & & & & \\
\hline \multirow[t]{3}{*}{ Imprisonment } & Yes & $115(12.7)$ & $21(18.3)$ & $15(13.0)$ & $13(11.3)$ & $5(4.4)$ & $6(5.2)$ & $4(3.5)$ & $8(7.0) * * *$ & $3(2.6)$ & $3(2.6)$ & $37(32.2)$ \\
\hline & No & $792(87.2)$ & $203(25.6)$ & $93(11.7)$ & $87(11.0)$ & $46(5.8)$ & $37(4.7)$ & $31(3.9)$ & $15(1.9)$ & $20(2.5)$ & $18(2.3)$ & $242(30.6)$ \\
\hline & Unknown & $1(0.1)$ & & & & & & & & & & \\
\hline \multirow[t]{3}{*}{ Malnutrition } & Yes & $464(51.1)$ & $116(25.0)$ & $50(10.8)$ & $46(9.9)$ & $25(5.4)$ & $20(4.3)$ & $19(4.1)$ & $14(3.0)$ & $12(2.6)$ & $13(2.8)$ & $149(32.1)$ \\
\hline & No & $442(48.7)$ & $108(24.4)$ & $58(13.1)$ & $54(12.2)$ & $26(5.9)$ & $23(5.2)$ & $16(3.6)$ & $9(2.0)$ & $11(2.5)$ & $8(1.8)$ & $129(29.2)$ \\
\hline & Unknown & $2(0.2)$ & & & & & & & & & & \\
\hline \multirow{3}{*}{$\begin{array}{l}\text { Reported } \\
\text { contact with a } \\
\text { TB patient }\end{array}$} & Yes & $246(27.1)$ & $67(27.2)$ & $30(12.2)$ & $28(11.4)$ & $15(6.1)$ & $12(4.9)$ & $11(4.5)$ & $3(1.2)$ & $7(2.9)$ & $8(3.3)$ & $65(26.4)$ \\
\hline & No & $661(72.8)$ & $157(23.8)$ & $78(11.8)$ & $72(10.9)$ & $36(5.5)$ & $31(4.7)$ & $24(3.6)$ & $20(3.0)$ & $16(2.4)$ & $13(2.0)$ & $214(32.4)$ \\
\hline & Unknown & $1(0.1)$ & & & & & & & & & & \\
\hline \multirow{2}{*}{$\begin{array}{l}\text { Any of } 7 \text { risk } \\
\text { factors }\end{array}$} & Yes & $695(76.5)$ & $175(25.2)$ & $82(11.8)$ & $76(10.9)$ & $41(5.9)$ & $32(4.6)$ & $30(4.3)$ & $17(2.5)$ & $16(2.3)$ & $20(2.9)$ & $206(29.6)$ \\
\hline & No & $212(23.4)$ & $49(23.1)$ & $26(12.3)$ & $24(11.3)$ & $10(4.7)$ & $11(5.2)$ & $5(2.4)$ & $6(2.8)$ & $7(3.3)$ & $1(0.5)$ & $73(34.4)$ \\
\hline
\end{tabular}


* This difference was statistically significant: $P=0.0424 ; * * P=0.0083 ; * * * P=0.0050$. 
Table 4. Drug susceptibility of MTB isolates of the most common spoligotypes (prevalence greater than 1\%) in Riga and Riga region, 2008-2012 $(n=908)$.

\begin{tabular}{|c|c|c|c|c|c|c|c|c|}
\hline SIT** & $\begin{array}{l}\text { Spoligotype } \\
\text { family }\end{array}$ & $\begin{array}{l}\text { Isolates in study, } \\
\text { No. }(\%)\end{array}$ & $\begin{array}{l}\text { Pan-susceptible, } \\
\text { No }(\%)\end{array}$ & $\begin{array}{l}\text { Drug-resistant*, } \\
\text { No }(\%)\end{array}$ & $\begin{array}{l}\text { MDR, } \\
\text { No }(\%)\end{array}$ & $\begin{array}{l}\text { XDR, No } \\
(\%)\end{array}$ & $\begin{array}{l}\text { Pan-susceptible/drug } \\
\text { resistant* } \\
\text { proportions within } \\
\text { SIT, \% }\end{array}$ & $\begin{array}{l}\text { MDR/XDR } \\
\text { proportions } \\
\text { within SIT, \% }\end{array}$ \\
\hline 1 & Beijing & $224(24.7)$ & $97(15.8)$ & $127(43.2)$ & $25(47.2)$ & $38(55.1)$ & $43.3 / 56.7$ & $11.2 / 17.0$ \\
\hline 20 & LAM & $10(1.1)$ & $9(1.5)$ & $1(0.3)$ & $1(1.9)$ & 0 & $90.0 / 10.0$ & $10 / 0$ \\
\hline 35 & Ural & $12(1.3)$ & $9(1.5)$ & $3(1.0)$ & $2(3.8)$ & 0 & $75.0 / 25.0$ & $16.7 / 0$ \\
\hline 40 & $\mathrm{~T}$ & $23(2.5)$ & $22(3.6)$ & $1(0.3)$ & 0 & 0 & $95.7 / 4.3$ & $0 / 0$ \\
\hline 42 & LAM & $51(5.6)$ & $22(3.6)$ & $29(9.9)$ & $9(17.0)$ & $18(34.0)$ & $43.1 / 56.9$ & $17.6 / 35.3$ \\
\hline 47 & Haarlem & $9(1.0)$ & $8(1.3)$ & $1(0.3)$ & 0 & 0 & $88.9 / 11.1$ & $0 / 0$ \\
\hline 50 & Haarlem & $11(1.2)$ & $8(1.3)$ & $3(1.0)$ & 0 & 0 & $72.7 / 27.3$ & $0 / 0$ \\
\hline 53 & $\mathrm{~T}$ & $100(11.0)$ & $83(13.5)$ & $17(5.8)$ & $4(7.6)$ & 0 & $83.0 / 17.0$ & $4 / 0$ \\
\hline 119 & $X$ & $21(2.3)$ & $20(3.3)$ & $1(0.3)$ & 0 & 0 & $95.2 / 4.8$ & $0 / 0$ \\
\hline 254 & LAM-RUS & $108(11.9)$ & $103(16.8)$ & $5(1.7)$ & 0 & $1(1.5)$ & $95.4 / 4.6$ & $0 / 0.9$ \\
\hline 262 & Ural & $23(2.5)$ & $22(3.6)$ & $1(0.3)$ & 0 & 0 & $95.7 / 4.3$ & $0 / 0$ \\
\hline 264 & LAM-RUS & $12(1.3)$ & $4(0.7)$ & $8(2.7)$ & $1(1.9)$ & $1(1.5)$ & $33.3 / 66.7$ & $8.3 / 8.3$ \\
\hline 283 & Haarlem & $43(4.7)$ & 0 & $43(14.6)$ & $3(5.7)$ & 0 & $0 / 100$ & $7.0 / 0$ \\
\hline 766 & LAM & $35(3.9)$ & $32(5.2)$ & $3(1.0)$ & 0 & $1(1.5)$ & $91.4 / 8.6$ & $0 / 2.9$ \\
\hline 1292 & Ural & $12(1.3)$ & $7(1.1)$ & $5(1.7)$ & 0 & 0 & $58.3 / 41.7$ & $0 / 0$ \\
\hline 3344 & Ural & $9(1.0)$ & $8(1.3)$ & $1(0.3)$ & 0 & 0 & $88.9 / 11.1$ & $0 / 0$ \\
\hline Others & & $205(22.6)$ & $160(26.1)$ & $45(15.3)$ & $8(15.1)$ & $10(14.5)$ & $78.0 / 22.0$ & $3.9 / 4.9$ \\
\hline Total & & 908 & 614 & 294 & 53 & 69 & $67.6 / 32.4$ & $5.8 / 7.6$ \\
\hline
\end{tabular}

* Including MDR and XDR isolates 
Table 5.

Cluster analysis of $M$. tuberculosis isolates by spoligotyping, 24-locus MIRU-VNTR and IS6110 RFLP genotyping methods.

\begin{tabular}{|c|c|c|c|c|}
\hline \multirow[t]{2}{*}{ Genotype (No. of strains)* } & & \multicolumn{3}{|c|}{ Genotyping method } \\
\hline & & Spoligotyping & MIRU-VNTR & IS6110 RFLP \\
\hline \multirow[t]{4}{*}{ Beijing (104) } & No. of clusters & 1 & 10 & 15 \\
\hline & No. of isolates in clusters & 101 & 69 & 55 \\
\hline & No. of genotypes & 4 & 45 & 64 \\
\hline & DP & 0.0571 & 0.8615 & 0.9776 \\
\hline \multirow[t]{4}{*}{ LAM (100) } & No. of clusters & 4 & 10 & 12 \\
\hline & No. of isolates in clusters & 94 & 66 & 59 \\
\hline & No. of genotypes & 10 & 44 & 53 \\
\hline & $\mathrm{DP}$ & 0.6263 & 0.9099 & 0.9459 \\
\hline \multirow[t]{4}{*}{ T family (91) } & No. of clusters & 8 & 11 & 14 \\
\hline & No. of isolates in clusters & 80 & 41 & 45 \\
\hline & No. of genotypes & 19 & 61 & 60 \\
\hline & $\mathrm{DP}$ & 0.6232 & 0.9829 & 0.9690 \\
\hline \multirow[t]{4}{*}{ Haarlem (27) } & No. of clusters & 5 & 2 & 2 \\
\hline & No. of isolates in clusters & 25 & 6 & 10 \\
\hline & No. of genotypes & 7 & 23 & 19 \\
\hline & $\mathrm{DP}$ & 0.7692 & 0.9801 & 0.9174 \\
\hline \multirow[t]{4}{*}{ Ural (46) } & No. of clusters & 4 & 5 & 6 \\
\hline & No. of isolates in clusters & 39 & 17 & 22 \\
\hline & No. of genotypes & 11 & 34 & 30 \\
\hline & $\mathrm{DP}$ & 0.7913 & 0.9797 & 0.9681 \\
\hline \multirow[t]{4}{*}{ X family (14) } & No. of clusters & 1 & 3 & 2 \\
\hline & No. of isolates in clusters & 13 & 6 & 12 \\
\hline & No. of genotypes & 2 & 11 & 4 \\
\hline & $\mathrm{DP}$ & 0.1429 & 0.967 & 0.6264 \\
\hline \multirow[t]{4}{*}{ Others (29) } & No. of clusters & 4 & 3 & 2 \\
\hline & No. of isolates in clusters & 9 & 8 & 4 \\
\hline & No. of genotypes & 24 & 24 & 27 \\
\hline & $\mathrm{DP}$ & 0.9852 & 0.9828 & 0.9951 \\
\hline \multirow[t]{4}{*}{ TOTAL (411 strains) } & No. of clusters & 27 & 44 & 53 \\
\hline & No. of isolates in clusters & 361 & 213 & 207 \\
\hline & No. of genotypes & 77 & 242 & 257 \\
\hline & DP & 0.8953 & 0.9846 & 0.9927 \\
\hline
\end{tabular}

* DP: discrimination power 


\section{Factor map (PCA)}

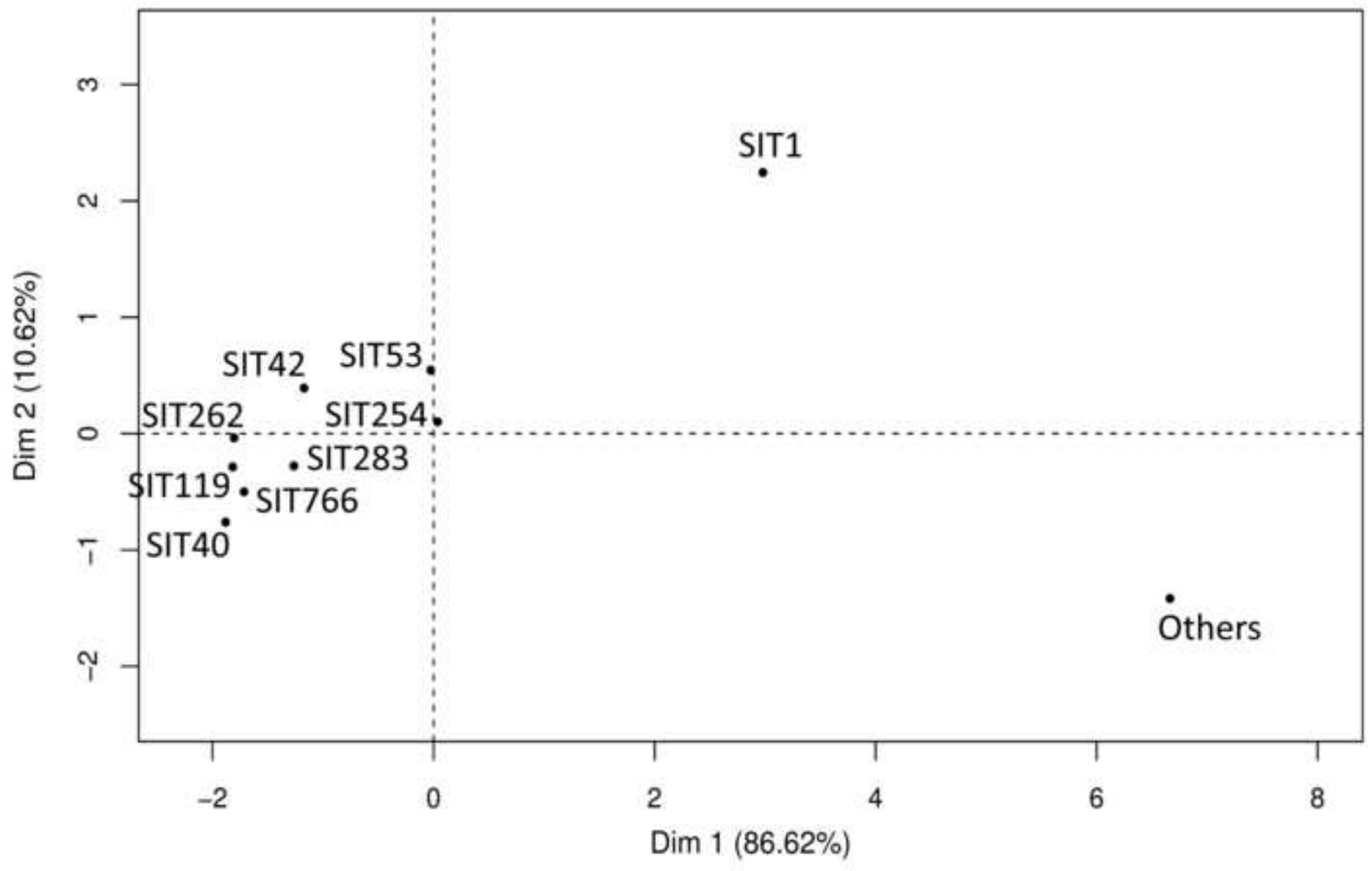




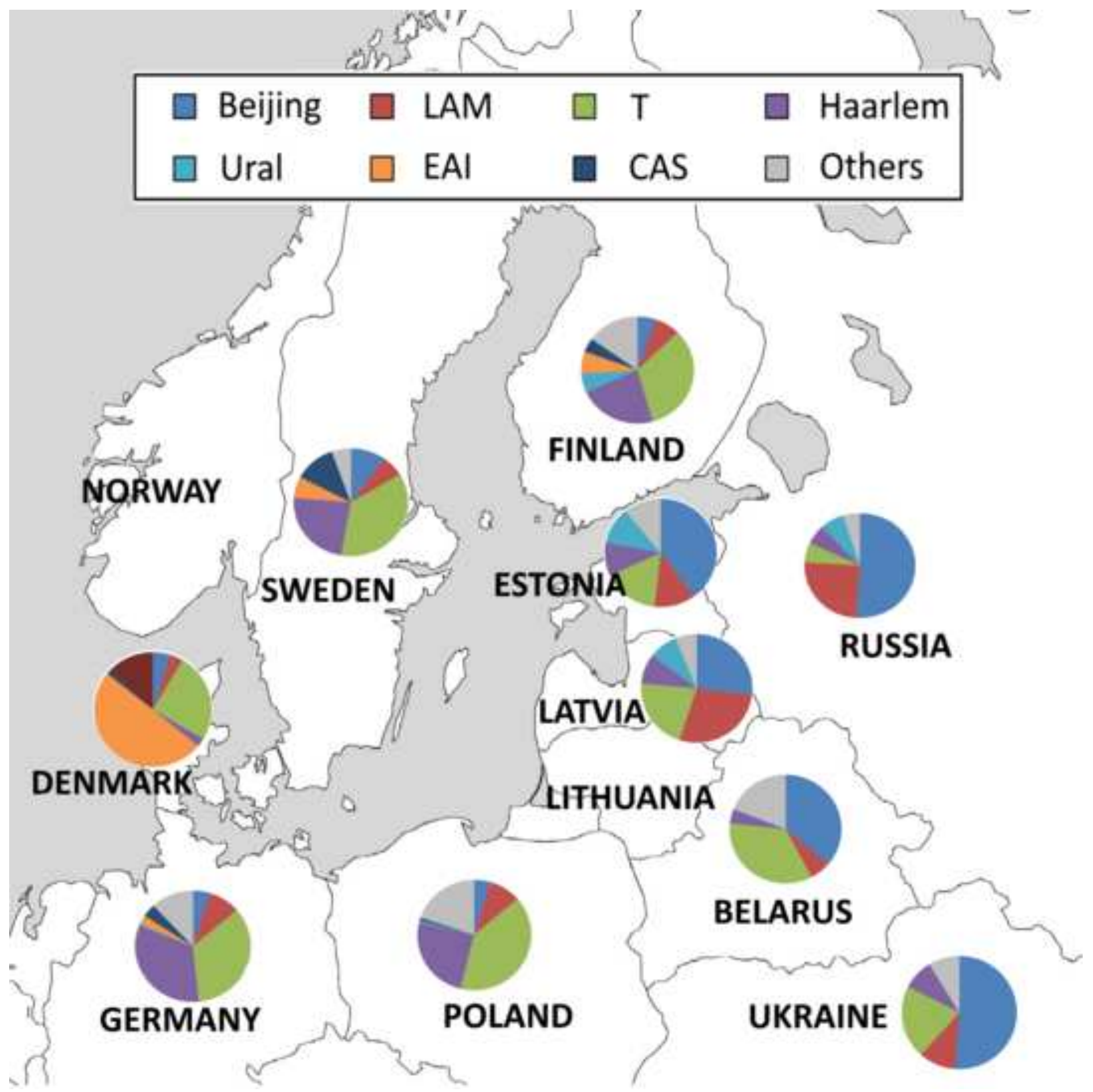


Supplementary Material
Click here to download Supplementary Material: Supplem_Table_S1_2019___.pdf

Supplementary Material
Click here to download Supplementary Material: Supplem_Table_S1_2019___.pdf

Supplementary Material
Click here to download Supplementary Material: Supplem_Table_S1_2019___.pdf 
Click here to download Supplementary Material: Suppl_Table_S2_new.pdf (n)

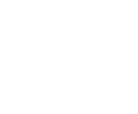


Supplementary Material
Click here to download Supplementary Material: Suppl_Table_S3.pdf (1) Click hes down . 西 西 西 . . . . . . . . . . . 
Supplementary Material
Click here to download Supplementary Material: Suppl_Table_S4.pdf

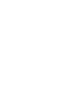

(2)

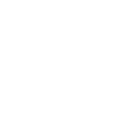
(n) (1)

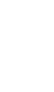

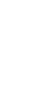
(1) (2)

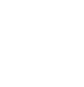


4 Analysis of Mycobacterium tuberculosis genetic lineages circulating in Riga and Riga

5 region, Latvia, isolated between 2008 and 2012.

6

7 The running title: Molecular epidemiology of tuberculosis in Latvia.

8

9 Ilva Pole $^{\text {a, b }}$, Julija Trofimova ${ }^{\text {a }}$, Inga Norvaisa ${ }^{\text {a }}$, Philip Supply ${ }^{\mathrm{c}}$, Girts Skenders ${ }^{\mathrm{a}}$, Anda

10 Nodieva $^{\mathrm{d}}$, Iveta Ozere ${ }^{\mathrm{a}, \mathrm{d}}$, Vija Riekstina ${ }^{\mathrm{a}}$, Viktorija Igumnova ${ }^{\text {b, d }}$, Jelena Storozenko ${ }^{\text {d, e }}$, Inta

11 Jansone ${ }^{\mathrm{b}}$, Ludmila Viksna ${ }^{\mathrm{d}, \mathrm{e}}$, Renate Ranka ${ }^{\mathrm{b}, \mathrm{d}}$

12

13 a - Riga East University Hospital, Centre of Tuberculosis and Lung Diseases;

14 b - Latvian Biomedical Research and Study Centre;

15 c - Univ. Lille, CNRS, Inserm, CHU Lille, Institut Pasteur de Lille, U1019 - UMR 8204 -

16 CIIL - Center for Infection and Immunity of Lille, F-59000 Lille, France;

17 d - Riga Stradiņš University;

18 e - Riga East University Hospital, Latvian Centre of Infectious Diseases.

20 Corresponding author:

21 Renate Ranka, PhD, Latvian Biomedical Research and Study Centre, Ratsupites Str. 1, Riga,

22 Latvia, LV-1067.Phone: 371 67808219, Fax: 371 67442407, e-mail: renate_r@biomed.lu.lv 


\section{Abstract}

25 Although the number of new tuberculosis (TB) cases registered per year has decreased by 3 fold between 2001 and 2017 in Latvia, the TB incidence and rates of multidrug resistant TB in this Baltic country remain substantially higher than in most other European countries. Molecular typing methods of Mycobacterium tuberculosis play an important role both in clinical studies of the disease and the epidemiological investigations, allowing to describe and characterize the pathogen's population structure and spread of particular genotypes. The aim of this study was to examine the prevalence of M. tuberculosis lineages in Riga and Riga region of Latvia within a five year period (2008 2012), and to evaluate the discriminatory power of spoligotyping, standard 24-locus MIRU-VNTR and IS6110-RFLP methods for genotyping of M. tuberculosis elinical isolates in this setting.

Analysis of spoligotyping results of 908 isolates showed that the main M. tuberculosis spoligotype families were Beijing and LAM (25.3\% and 24.3\%, respectively) followed by T (22.1\%), Ural (11.2\%), Haarlem (6.6\%) and X superfamily (3.4\%). This distribution remained similar over the five consecutive years. Analysis of possible associations between spoligotypes and TB patients' characteristics revealed some age-related differences. Moreover, SIT53 (T) and SIT1 (Beijing) spoligotypes were more often detected among homeless patients and patients with permanent home, respectively $(\mathrm{P}=0.0083$ and $\mathrm{P}=0.0424$, respectively), and SIT262 was more eften identified in former imprisoners $(7.0 \%$ vs $1.9 \%, \mathrm{P}=0.005)$. Spoligotyping, MIRU VNTR and IS6110 RFLP results were available for a total of $411 \mathrm{M}$. mberculosis clinical isolates. Overall, the discriminatory power of spoligotyping method alone was 0.8953 , but was very low in case among Beijing family isolates, as expected. The 

$47(\mathrm{DP}=0.9846$ and 0.9927 , respectively $)$, mainly due to the improvement of the resolution for the
In conclusion, this work represents the first comprehensive molecular epidemiologicat eirculating in Riga and Riga region. In combination with detailed epidemiological data this approach was helpful for the in-depth understanding of epidemiological processes in settings where the Next-Gen sequencing is not available as a routine method.
Although the number of new tuberculosis (TB) cases registered per year has decreased by 3 -fold between 2001 and 2017 in Latvia, the TB incidence and rates of multidrug resistant TB in this Baltic country remain substantially higher than in most other European countries. Molecular $\underline{\text { studies of the disease and the epidemiological investigations, allowing to describe and }}$ typing methods of Mycobacterium tuberculosis (MTB) play an important role both in clinical characterize the pathogen's population structure and spread of particular genotypes. Aim of this study was to examine the prevalence of MTB lineages in Riga and Riga region of Latvia within a five-year period (2008 - 2012), and to evaluate the discriminatory power (DP) of spoligotyping, standard 24-locus MIRU-VNTR and IS6110-RFLP methods in this setting.
The results showed that the main MTB spoligotype families were Beijing (25.3\%) and LAM (24.3\%), followed by T (22.1\%), Ural (11.2\%), Haarlem (6.6\%) and X superfamily (3.4\%). This distribution remained stable over the five consecutive years. $67.6 \%$ of MTB isolates were pan- susceptible, and $32.4 \%$ were resistant to any drug; multi-drug resistance was found in $5.8 \%$ of MTB strains, and $7.6 \%$ of MTB isolates were extensively drug-resistant. Drug resistance was associated with SIT1, SIT283 and SIT42 genotypes, while SIT1 and SIT42 were overrepresented among multi drug-resistant MTB strains. Overall, DP of spoligotyping method alone was 0.8953 ,


71 while DP of both 24-locus MIRU-VNTR analysis and IS6110 RFLP was higher (DP=0.9846 and

72 0.9927, respectively), mainly due to the improvement of the resolution for the Beijing strains.

73 In conclusion, this work represents the first comprehensive molecular epidemiological

74 description of TB in Latvia, highlighting the high genetic diversity of MTB strains circulating in

$75 \quad$ Riga and Riga region. In combination with detailed epidemiological data this approach was

76 helpful for the in-depth understanding of epidemiological processes in settings where the Next-

77 Gen sequencing is not available as a routine method.

78 


\section{Introduction}

The epidemiological situation of tuberculosis (TB) in Latvia, a country in the Baltic

81

82 region of the northeastern Europe, during the last decade has improved, with 1729 (73.5 per 100 000 population) and 483 (24.8 per 100000 population) new cases registered in year 2001 and 2017, respectively. However, this incidence remains substantially above the average incidence in most other European countries. Furthermore, Latvia is among the multidrug-resistant tuberculosis (MDR-TB) middle burden countries in the world: there were $36(7.5 \%)$ notified MDR TB cases in 2017 (data from The Centre for Disease Prevention and Control of Latvia). Molecular typing methods of Mycobacterium tuberculosis (MTB) isolates play an important role both in clinical studies of TB and in epidemiological investigations. The description of predominant MTB lineages, diversity of strains and clustering rates is necessary for monitoring the spread of TB in a particular geographic region or epidemiological settings. While several genotyping methods are available to date, all these methods have their own particular advantages and disadvantages in particular settings and they differ with their sensitivity, reproducibility, resolution, and discriminatory power (DP) (Supply et al., 2000; van Soolingen, 2001; Supply et al., 2001; Gori et al., 2005; Supply et al., 2006; reviewed in Merker et al., 2017). Compared to classical typing methods, whole genome sequencing (WGS) method provides the most precise and comprehensive identification and characterization of MTB strain genotypes. However, several barriers for clinical adoption exists including costs and the lack of bioinformatic expertise among clinical microbiologists (Satta et al., 2018). Among the classical typing methods, restriction fragment length polymorphism analysis of IS6110 (IS6110-RFLP), which have been previously known as the first gold standard for MTB strain typing, is timeconsuming and needs good quality, purified and concentrated DNA (van Soolingen, 2001). PCR- 
102 based methods such as spoligotyping (Kamerbeek et al., 1997) and 24-locus mycobacterial

103 interspersed repetitive unit variable-number tandem repeat (MIRU-VNTR) typing (Supply et al.,

104 2006) are rapid, easily performed, and can be done with very small quantities of crude DNA

105 extracts. Because of its resolution power, generally superior compared to spoligotyping and in

106 the same range as IS6110 RFLP (Supply et al., 2006; De Beer et al., 2013), molecular clustering

107 based on the latter method has been and is still largely used as a proxy to identify recent

108 transmission of MTB strains, when WGS is not accessible.

109 Riga is the capital of Latvia and is also the largest city in the Baltic States. With

110 approximately one million inhabitants (year 2017), Riga city and Riga region is home to $\sim 52 \%$

111 of Latvia's population (Central Statistical Bureau of Latvia, csb.gov.lv.). The aim of this study

112 was to examine the prevalence of MTB lineages in Riga and Riga region of Latvia within the

113 five year period (2008 - 2012), and to evaluate the DP of spoligotyping, MIRU-VNTR and

114 IS6110 RFLP methods for genotyping of MTB clinical isolates in this specific setting. This is

115 the first comprehensive molecular epidemiological study of TB in Latvia.

\section{2. Materials and methods}

119 2.1. Study Setting and Design

120 The Center of Tuberculosis and Lung Diseases, Riga East University Hospital plays a central

121 role in TB management in the country. The Center handles all MTB isolates for the Riga and 122 Riga region, and oversees routine diagnosis, and provides phenotypic drug sensitivity testing.

\section{$123 \quad$ 2.2. Mycobacterial isolates and epidemiological data}


124 The source of the MTB isolates was mainly sputum or induced sputum, and occasionally other

125 biological samples such as urine, faeces, bronchial aspirates, biopsy samples, pleural effusion

126 and operation material, from TB patients living in Riga and Riga region and admitted to Center

127 of Tuberculosis and Lung Diseases, Riga East University Hospital between January 2008 and

128 December 2012. Patient diagnosis was confirmed both microscopically and by culturing on solid

129 Lowenstein-Jensen (LJ) medium for 4-6 weeks. Only one isolate from each patient at time of

130 diagnosis was included in this study.

131 Epidemiological and clinical data for this study was provided by the National TB registry of

132 Latvia.

133

$134 \quad$ 2.3. DNA extraction and genotyping

135 Mycobacterial chromosomal DNA was isolated from mycobacterial colonies grown on

136 Lowenstein Jensen (LJ) media using Cetyltrimethyl Ammonium Bromide (CTAB) method

137 (van Soolingen et al., 1991). Spoligotyping was used to identify MTB genotype for all

138 available clinical isolates. Spoligotyping was performed using commercially available kits

139 (Isogen Life Science, Netherlands; later Ocimum Biosolutions, India) following previously

140 described standard protocol (Kamerbeek et al., 1997). Spoligotyping results were analysed

141 and compared with those in SITVIT2 MTBC database was used for discrimination of MTB

142 spoligotype families (SIT numbers and families) (Couvin D et al., 2018).

143 24-locus MIRU-VNTR typing was performed using PCR followed by capillary sequencer

144 analysis, as described in (Supply et al., 2006). The 24-allele profiles were analyzed with the

145 tools implemented in the MIRU-VNTRplus online database (Weniger et al., 2010). 
DNA fingerprinting with IS6110 as a probe was performed by using standardized protocols as

147 described elsewhere (van Embden et al., 1993). The BioNumerics software Version 5.3

(Applied Maths NV, Sint-Martens-Latern, Belgium) was used for data analysis.

\subsection{Drug susceptibility testing}

MTB drug susceptibility testing (DST) for the 1st line (isoniazid, rifampicin, ethambutol and

pyrazinamide) and 2nd line drugs (streptomycin, ofloxacin, kanamycin, amikacin,

capreomycin, ethionamide, cycloserine; para-aminosalicylic acid) was carried out for all

$\underline{\text { strains using the method of absolute concentrations on the solid LJ medium and Bactec MGIT }}$

960 system (Becton Dickinson, Heidelberg, Germany) according to WHO recommendations

(WHO, 2018). The laboratory is externally quality assured according to the requirements of

\subsection{Statistical analysis}

The 2-sided Fisher's exact test was employed to determine a $P$ value (GraphPad Software, La

Jolla, California, USA). A $P$ value equal to or less than 0.05 was considered significant. The

161 distribution of the spoligotypes among different age groups was analyzed with principal

162 components analysis (PCA) in R using FactoMineR (Lê et al., 2008). The discriminatory

163 power of each method was calculated by the Hunter-Gaston discriminatory index (HGDI). 


\section{Results}

\subsection{Epidemiological data of TB patients}

167 From January 2008 to December 2012, 4241 new TB cases were recorded in Latvia including

1625 TB cases (38.3\%) in Riga and Riga region. Among these cases 7.71\% (327/4241) were children (age 0 - 17 years); in Riga and Riga region the proportion of pediatric cases was $9.17 \%$ (149/1625). In total, in Riga and Riga region, 1308 cases were culture-positive, and 908 MTB clinical isolates were available for this study.

Among them, 1308 cases were culture positive, and a total of 908 MTB clinical isolates were available for this study.

Table 1 presents an overview of the demographic and clinical characteristics of culture-positive TB patients included in this study. The male/female ratio was 581/327, the median age was 42 (1-89 years old). The majority of patients were $21-60$ years old (775 individuals, $85.3 \%$ ) and were born in Latvia (813 individuals, 89.5\%). Within the youngest age group (i.e. individuals 020 years old) 16 MTB isolates were from children. Pulmonary TB was diagnosed in $861(94.8 \%)$ cases, while $13(1.4 \%)$ patients had extra-pulmonary TB. Both types of disease were diagnosed in $33(3.6 \%)$ individuals.

\subsection{MTB isolate diversity by spoligotyping}

Spoligotyping analysis of 908 MTB clinical isolates revealed a total of 138 different patterns (DP: 0.9034) (Supplemental Table S1).

Of 908 isolates, 821 isolates were divided into 51 clusters (cluster size 2-224 isolates). In total, 846 samples (93.2\%) showed shared-types or SITs when compared to the SITVIT2 MTBC database. In contrast, only 11 MTB isolates (1.2\%) belonged to known orphan spoligotypes, 
while 51 isolates (5.6\% of all samples) corresponded to a total of 38 new spoligotyping patterns that have not yet been reported (Supplemental Table S1). The spoligotyping results showed that almost equal proportions of MTB strains, Latvia, belonged to the Beijing and LAM lineages in Riga and the Riga region (25.4\% and 26.5\%, respectively) followed by T lineage (20.3\%) (Table 2). Less prevalent genotypes in Riga region were Haarlem (8.5\%), Ural (7.9\%) and $X$ superfamily (2.4\%), while Central Asian and East-African Indian strains were absent. Other spoligotypes accounted for $8.9 \%$ of all MTB isolates analysed. The distribution of the MTB spoligotype families within the 5 year period was further analyzed, and the results are shown in Table 2. A slight fluctuation in the distribution of MTB families within different years was observed, however, this difference was not statistically significant $(P>0.05)$. Similarly, fluctuations in the distribution of most prevalent MTB spoligotypes (prevalence $\geq 1 \%$ ) within this $\underline{\text { study period were not statistically significant (Supplemental Table S2). }}$

The Beijing family was represented by four spoligotypes; SIT1 was the dominant spoligotype as it was detected in 224 (24.7\%) of all studied clinical isolates. SIT190 was found in only three samples $(0.3 \%)$, while both SIT255 and SIT265 spoligotypes were detected in 2 samples each $(0.2 \%)$. By contrast, higher spoligotype diversity was observed for LAM, T, and Haarlem families. The LAM family comprised 241 clinical isolates and was represented by 19 spoligotypes including isolates belonging to LAM-RUS spoligotypes SIT254, 264, 496, 1240 and 2246. Further, 184 MTB isolates that belonged to the T family showed 32 different spoligotypes, while the Haarlem family consisted of 77 studied isolates and was represented by 13 spoligotypes (Supplemental Table S1). Overall, spoligotypes with a prevalence greater than 10\% among all isolates included SIT1 (Beijing, 24.7\%), SIT254 (LAM-RUS, 11.9\%) and SIT53 (T family, 11.0\%), while spoligotypes with a prevalence greater than $2 \%$ included 
211 SIT42, SIT283, SIT766, SIT262, SIT40 and SIT119; other spoligotypes with a prevalence

212 lower than 2\% were represented by $280(30.8 \%)$ MTB isolates in total (Table 1).

\section{3.3. Association between spoligotypes and TB patients`characteristics}

215 Possible associations between spoligotypes and TB patients`characteristics were analyzed by 216 PCA analysis followed by statistical evaluation. Upon PCA analysis, age-related differences

217 were interestingly revealed among spoligotype patterns. In a score plot, the spoligotype SIT1 218 as well as spoligotypes with a prevalence less than $2 \%$ in the population (collectively named 219 as others in Fig. 1) were clearly separated; on the other hand, the PCA showed very close 220 distances between SIT254, SIT53, SIT42, SIT283, SIT766, SIT262, SIT40 and SIT119 for the

221 age groups studied (Figure 1). Indeed, the prevalence of SIT1 in the individuals who were 222 older than 60 years of age was decreased, while the prevalence of rare spoligotypes in older 223 individuals was significantly increased in comparison with young (age $\leq 20$ years old) patients $224(P=0.0374)($ Table 1$)$.

225 In contrast, the data analysis revealed no differences of the distribution of spoligotypes among 226 male and female patients. Similarly, no significant differences were observed between Latvia227 born and foreign-born individuals, and for the type of the disease (Table 1).

\subsection{Association between spoligotypes and TB risk factors}

230 Further, possible association between spoligotypes and TB risk factors was explored. In this 231 study, seven different TB risk factors were analyzed which were included in the National TB 232 registry of Latvia since year 2000: housing status, alcohol abuse, drug abuse, HIV infection, 233 imprisonment, malnutrition and reported contact with a TB patient (Table 3). The majority of 
234 patients had a permanent home $(92.2 \%)$, while $70(7.7 \%)$ patients were homeless. Of the patients 235 for whom HIV status was known (99.7\%), 139 (15.3\%) individuals were HIV-positive. Alcohol 236 abuse as a risk factor was detected for 270 (29.7\%) patients, while $115(12.7 \%)$ individuals were 237 recorded as being in prison, and $79(8.7 \%)$ - using drugs. Malnutrition was recorded for a half of 238 all patients $(51.1 \%)$, while less than $30 \%$ of individuals have reported the contact with TB 239 patient $(27.1 \%)$. The presence of any of these seven TB risk factors was detected in the majority 240 of patients $(76.5 \%)$. Overall, the prevalence of the main spoligotypes among individuals with 241 risk factors was similar to those observed in non-risk patients $(P>0.05)$ (Table 3$)$. However, 242 statistically significant difference was detected in the prevalence of both SIT1 and SIT53 243 spoligotypes depending on the housing status of the patients: SIT53 was more often present in

244 the homeless persons, and SIT1 was more often present in patients with permanent home $245(P=0.0083$ and $P=0.0424$, respectively). In addition, the spoligotype SIT262 was more often 246 detected in former imprisoners $(7.0 \%$ vs $1.9 \%, P=0.005)$.

\subsection{Drug resistance analysis}

Analysis of drug resistance profiles showed that $67.6 \%$ of MTB isolates were pan-susceptible $\underline{(n=614)}$ and $32.4 \%$ were resistant to any drug $(n=294)$ (Table 4). The distribution of spoligotypes among drug resistant isolates was as follows: 43.2\% SIT1 (Beijing, $\mathrm{n}=127$ ), 9.9\% SIT42 (LAM family, n=29), 5.8\% SIT53 (T family, $n=17), 14.6 \%$ SIT283 (Haarlem, n=43); all other spoligotypes accounted for 26.5\% (n=78) of drug-resistant MTB strains. Spoligotypes with

a drug resistance prevalence greater than $30 \%$ among the isolates included SIT1 (Beijing, 
$\underline{\text { SIT1292 (Ural, 41.7\%); statistically significant difference was reached for SIT1, SIT42 and }}$

$\underline{\text { SIT283 }}(\mathrm{P} \leq 0.05 ;$ Table 4$)$.

In total, MDR and extensively-drug-resistance (XDR) was found in 5.8\% (53/908) and 7.6\%

(69/908) of MTB strains, respectively.

The analysis of the distribution of spoligotypes among MDR/XDR isolates showed a significant overrepresentation of both SIT1 and SIT42 isolates: these spoligotypes accounted for $47.2 \%$ and

$17.0 \%$ of MDR MTB, and for $55.1 \%$ and $34.0 \%$ of XDR strains, respectively (Table 4).

\section{3.모. Analysis of MTB isolates by different genotyping approaches}

From 908 MTB isolates, 411 samples were available for additional IS6110 RFLP and MIRUVNTR analyses and thus were used for more in-depth genotypic characterization of MTB isolates in Riga and Riga region. In total, these samples represented 25.3\% of all MTB-positive cultures isolated in the $2008-2012$ time period. Among them, 78 spoligotypes were identified. The isolates belonged to the following MTB families: Beijing ( $\mathrm{n}=104 ; 25.3 \%), \mathrm{T}(\mathrm{n}=91 ; 22.1 \%)$, LAM $(n=100 ; 24.3 \%)$, Haarlem $(n=27 ; 6.6 \%)$, Ural $(n=46 ; 11.2 \%)$ and $X(n=14 ; 3.4 \%)$; the remaining 29 (7.1\%) represented other families and/or unpublished SITs (Table 2). This overall representation of spoligotypes for these 411 isolates was similar to that observed for the full MTB dataset, indicating that this selection was quite representative of the total strain set. Spoligotyping alone identified 78 genotypes, 50 of which were unique; $87.8 \%$ of isolates (361 of 411) formed 27 clusters with a cluster range 2-31 samples.

Upon 24-locus MIRU-VNTR typing, 242 different MIRU-VNTR patterns were obtained; 213 MTB isolates (51.8\%) were grouped into 44 clusters with 2 to 37 isolates per cluster, while the remaining 198 samples showed a unique MIRU-VNTR profile (Table $\underline{54}$; Supplemental Table 
292 (7.0\%).

3z). Thus, MIRU-VNTR typing had a substantially greater $\mathrm{DP}(\mathrm{DP}=0.9846)$ in comparison with spoligotyping $(\mathrm{DP}=0.8953)$.

When 24 MIRU-VNTR-based cluster analysis was performed for the main MTB families separately, the Beijing family isolates $(n=104)$ were divided into 45 different MIRU-VNTR genotypes, forming ten clusters and 35 unique genotypes. According to the MLVA MtbC15-9 nomenclature implemented in the MIRU-VNTR Plus database, the 3 most common allelic profiles were: (1) 94-32 (244233352644425153353823) represented by 37 isolates (35.6\%); (2) 100-32 (244233352644425173353723) represented by 11 isolates (10.6\%); and (3) 170-32 (244243352544425153353823) represented by 5 isolates (4.8\%) (Table 5 4 ; Supplemental Table $\underline{32})$. MTB isolates of the LAM lineage $(n=100)$ were divided into 44 MIRU-VNTR genotypes forming ten clusters with 2-25 members and 34 unique genotypes. The 3 most common genetic profiles were following: (1) 121-52 (132244332224125153322622) represented by 25 isolates $(24.0 \%)$; (2) 843-52 (132254332224125153322622) represented by 15 isolates (15.0\%); (3) 15664-52 (132244332224125153321622) represented by 7 isolates (7.0\%).

293 In contrast, MIRU-VNTR types within the other spoligotype families were relatively more 294 diverse/less clustered. For instance, MTB isolates of T family (n=91) were divided into 61 295 MIRU-VNTR genotypes, forming 11 clusters and 50 unique genotypes. The 3 most common 296 genotypes were represented by 5 (5.5\%; 20574-15, 223114322534425153342512), 6 (6.6\%;

297 12677-15, 224243122334225143334322) and 7 isolates (7.7\%; 20556-15,

298 224243122434225143335322), respectively. Likewise, the largest cluster observed among the 299 isolates part of the Haarlem spoligotype family $(n=27)$ comprised only 4 isolates $(14.8 \%$; $3003527-15,223235332434425153324732)$ ), while a second cluster included only 2 isolates 
301 (7.4\%). The Ural MTB family members $(\mathrm{N}=46)$ formed five clusters, of which 2 were of four 302 isolates each (163-15, 235237232244425113323632 and 16668-15,

303 215237232244425113323732); three other clusters had three isolates each. The X family

304 members $(n=14)$ have formed three clusters which had only two isolates each (Supplemental 305 Table $\underline{3} z)$.

306 Next, we applied IS6110 RFLP typing to all 411 isolates. In total, 257 different patterns were 307 obtained. 207 isolates (50.4\%) were grouped into 53 clusters, and the calculated DP for the 308 RFLP genotyping method in our dataset was as high as 0.9927 (Table 54). Importantly, in the 309 case of Beijing strains, IS6110 RFLP typing showed superior resolution of the genotypes

$310(\mathrm{DP}=0.9766)$ to both spoligotyping and MIRU-VNTR typing $(\mathrm{DP}=0.0571$ and 0.8615 , 311 respectively).

312 When all three genotyping methods were combined, only 119 MTB isolates (29.0\%) were 313 grouped into 39 clusters with 2 to 12 isolates per one cluster, while the remaining 292 samples 314 have shown a unique RFLP and/or MIRU-VNTR/spoligotype patterns (Supplemental Table 315 43). The largest cluster was composed of 12 MTB isolates belonged to SIT254 (representative 316 of LAM-RUS family). In total, the LAM lineage isolates formed 9 clusters with 2-12 isolates, 317 the Beijing genotype isolates - 9 clusters (2-8 isolates), T family - 11 clusters (2-4 isolates), 318 Ural - four clusters (2-3 isolates), and X - three clusters with 2, 3 and 4 isolates each. In 319 addition, two clusters with two isolates each were obtained for the new spoligotypes 320 (spoligotype 757777777720761 and 477777663760771$)$ (Supplemental Table 4 3 ).

\section{4. Discussion}


323 Although MTB genotypes were previously studied in association with drug resistance in

324 Latvia (Tracevska et al., 2003; Nodieva et al., 2010; Bauskenieks et al., 2014), this is the first

325 comprehensive report describing the molecular epidemiology of TB in Riga and Riga region,

326 which is home for more than $50 \%$ of Latvia's population. The analysis of the prevalence of the

327 main MTB spoligotypes within the five-year time frame revealed the presence of 138

328 spoligotypes. Among them, 38 spoligotypes representing 5.6 percent of the 908 study isolates

329 had not been previously reported to the global SITVIT database. At the other extremity, the 3

330 most common spoligotypes, namely SIT1 (Beijing family), SIT53 (T family) and SIT254

331 (LAM family) accounted altogether for approximately one-half of all MTB isolates, and

332 represented $24.7,11.0$ and $11.9 \%$ of isolates, respectively. These patterns are also among the

333 most common SITs in the world (Demay et al., 2012). In addition to be dominant in East Asia,

334 strains with the canonical Beijing SIT1 spoligotype are present in all seven geographic areas

335 of the world (Merker et al, 2015). In Europe, Beijing isolates were previously reported to be

336 very common in the Latvia's eastern and northern neighboring countries, Russia and Estonia,

337 often in association with drug resistance (Toungoussova et al., 2002; Kruuner et al., 2001). In

338 Latvia, too, Beijing genotype was prevalent among MDR-TB patients (Tracevska et al., 2003).

339 More recent data indicated that the XDR M. tuberculosis strain population in northwestern

340 Russia is heavily dominated by Beijing genotype isolates (Vyazovaya et al., 2015). In Pskov

341 oblast, which is located in northwestern Russia on the Russian/Latvian border, the Beijing

342 genotype was the most prevalent followed by LAM, T, Haarlem, Ural, and Manu2 families

343 (Mokrousov et al., 2012).

344 In this study, in total, $32.4 \%$ of MTB isolates were resistant to any drug, and $13.4 \%$ were

345 MDR/XDR strains. Unsurprisingly, Beijing genotype was highly associated with drug 
346 resistance, as $43.2 \%$ of drug-resistant isolates belonged to the spoligotype SIT1. SIT1 was also the predominant genotype among MDR/XDR isolates: approximately half of all MDR and XDR isolates (i.e. $47.2 \%$ and $55.1 \%$, respectively) belonged to this spoligotype. While SIT1

was also the most common spoligotype in our study, the predominance of this genotype among drug-resistant isolates is not related only to the simple majority. The analysis of drug $\underline{\text { resistance profiles showed that resistance to any drug and MDR/XDR phenotype was observed }}$ in $56.7 \%$ and $28.1 \%$ of the SIT1 strains, respectively. Both proportions were statistically larger when compared to the proportion of drug-resistant and MDR/XDR strains among the total number of MTB isolates (i.e. 32.4\% and 13.4\%, respectively). MIRU-VNTR analysis of Beijing isolates in Latvia showed the dominance of MTB strains belonged to clusters 94-32

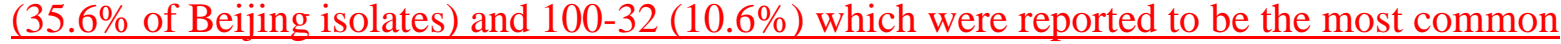
cross-border molecular clusters of MDR TB in Europe (ECDC, 2016). Similarly, Beijing clusters 94-32 and 100-32 were the dominant MTB genotypes in Central Asia, and the clonal spread of resistant TB strains, particularly of the Beijing lineage, was highlighted as a root of drug-resistant TB in Latvia. Less prevalent genotypes among drug-resistant isolates were SIT283 (Haarlem, 14.6\%), SIT42 (LAM, 9.9\%), SIT53 (T family, 5.8\%) and SIT264 (LAM$66.7 \%$ and $100 \%$, respectively), as well as the proportion of MDR/XDR isolates among SIT42 samples (52.9\%) was significantly increased. Along with Beijing strains, the combination of 
the two most common types were 121-52 and 843-52, which accounted for $25.0 \%$ and $15.0 \%$

of LAM isolates, respectively. While SIT254 was not associated with drug resistance, as

95.4\% of isolates were pan-susceptible in our study, the distribution of other LAM family

genotypes, including SIT42 and SIT264, is of high importance. These findings indicate that

the high burden of TB drug resistance in Latvia is at least partially related to the circulation of

MTB strains of specific genotypes. Thus, genotyping of MTB strains is highly important to

identify significant factors involved in the distribution of resistance strains which, in turn, may

affect TB control programs.

Overall, the prevalence of different genotype families in Latvia seen in this study resembles those reported for the neighboring Estonia, northwestern Russia and, to a smaller extent, Belarus and Ukraine (where Ural genotypes were not observed according to previous reference reports) (Figure 2) (Chernyaeva et al., 2012; Mokrousov et al., 2012; Toit et al., 2014; Zalutskaya et al., 2013; Nikolaevskaya et al., 2016;). Relatively to these Baltic and Eastern countries, the prevalence of Beijing genotypes is substantially lower in Western Europe and Scandinavia, and the proportion of isolates with spoligotype patterns typical of the Euro-American lineage (alias lineage 4) of M. tuberculosis is archetypally much higher (Figure 2) (Demay et al., 2012; Smit et al., 2013).

Interestingly, among the 51 isolates with a total of 38 novel spoligotypes that were discovered among circulating MTB strains in Riga region, six shared the same spoligotype 477777663760771, unreported in any other world place thus far. These isolates might thus represent a genotype specific to Latvia. Further studies would help to explore the frequency and underlying clonal/genome diversity of this spoligotype more in details. 
Importantly as well, the distribution pattern of the most common genotypes with a

392 dominance of Beijing, LAM and T spoligotypes remained stable over the five-year study period, indicating an overall unchanged prevalence and circulation of different MTB strains in the country and society. Similar result was obtained for the distribution of the most common spoligotypes including drug resistance-related SIT1, SIT42 and SIT283. This stability at least within this time span limits contrasts with the substantial changes in MTB strain population structures observed over time in other European countries like Ireland and Germany, associated with human migration and mobility (Roycroft et al., 2018; Andrés et al., 2017). These results is consistent with the fact that the vast majority of TB patients in this study, i.e. $89.5 \%$, were local born.

While we did not find any associations of spoligotypes with patients` characteristics such as gender, country of birth or type of the disease, our PCA results showed that the SIT1 spoligotype is more frequent in $21-50$ year-old adults while the rare spoligotypes were more frequent in elderly patients. In keeping with the notion that the majority of infected individuals remain asymptomatic over most or all of their lifetime (Zumla et al. 2013), and many of the TB cases in the elderly result from reactivation of a latent MTB infection acquired at much younger ages (Negin et al. 2015), the association of these rare spoligotypes with older patients might reflect genotypes that were more prevalent in the past but have become less abundant nowadays.

We also found that SIT53 (T family, representing a generic spoligotype signature that can be shared by different branches of the Euro-American lineage of M. tuberculosis) isolates were more common in homeless patients, while SIT1 spoligotype (Beijing family) was significantly more frequent in patients with permanent home than in homeless persons, and 
414 SIT262 (Ural family) was associated with imprisonment. Prisons are settings in which TB

415 transmission occurs and the incidence of TB in prisons is typically several fold higher

416 compared to the general population (reviewed in Biadglegne et al., 2015). Ural family strains

417 have not previously been associated with increased transmissibility (Mokrousov, 2012).

418 However, additional environmental, social, and host related risk factors (like history of

419 previous imprisonment in other (Eastern) countries, of contacts with prisoners with such a

420 history) could facilitate the spread of particular TB strains in these places (Biadglegne et al.,

421 2015). Similarly, low socioeconomic status and enhanced exposure in crowded places such as

422 homeless shelters may have an impact on the transmission dynamics of particular strains (part

423 of the Euro-American lineage in this case) in specific patient groups, such as homeless people.

424 Also, recent report of Sinkov and colleagues highlighted the recent emergency of Ural Clade C

(belongs to SIT262) in Eastern European countries Moldova and Belarus which was

significantly associated with XDR or pre-XDR status (Sinkov et al., 2019). In our study, the

majority of SIT262 isolates were pan-susceptible (22 of 23), while drug resistant strains

including those with MDR phenotype were found among isolates belonging to other Ural

family spoligotypes SIT35, 1292 and 3344. These findings demonstrated the circulation of

$\underline{\text { Ural strains with concern for drug resistance and the need for detection and surveillance of }}$

$\underline{\text { these strains in Eurasia to prevent further dissemination. }}$

Consistently with multiple previous studies, our results show that, although it is a rapid

433 and convenient genotyping method for broad identification of genotype families in clinical

434 strains (Gori et al., 2005) (Millet et al., 2007), spoligotyping cannot be used alone in order to

435 investigate the possible epidemiological links between patients, especially in settings

436 dominated by the Beijing lineage. Isolates with Beijing spoligotypes were the most common in 
437 our study, resulting in a spoligotyping clustering rate of 97.1\% (101/104 isolates) and a

438 calculated DP for as low as 0.057 for these isolates. Unsurprisingly as well, the 24-locus

439 MIRU-VNTR analysis clearly increased the overall resolution of the obtained MTB genotypes

440 (calculated DP=0.9846), and especially among isolates with a Beijing spoligotype with a

441 resulting clustering rate of 66.4\% (69/104) among them. Likewise, IS6110 RFLP typing had a

442 much higher resolution in comparison with spoligotyping ( $\mathrm{DP}=0.9927)$, and in the case of

443 Beijing lineage the DP was the highest among the methods applied ( $\mathrm{DP}=0.9766)$. Given that

444 spoligotyping is both an appropriate routine method for a clinical laboratory in Latvia and a

445 useful screen to identify geneotype families, a combination of this method with at least one of

446 the two other molecular genotyping approaches should be used in order to correctly interpret

447 typing results for the needs in epidemiological tracing.

448 In conclusions, we report the first comprehensive molecular epidemiological study of TB

449 in Latvia. This study highlighted the high genetic diversity of $M$. tuberculosis strains circulating

450 in Riga and Riga region. The combination of the spoligotyping with the 24-locus MIRU-VNTR

451 and IS6110 RFLP clearly increased the overall resolution of the MTB genotypes. In combination

452 with detailed epidemiological data, this approach was helpful for a first in-depth understanding

453 of epidemiological processes in a settings where the Next-Gen sequencing is not available as a

454 routine method.

455

456

457 Acknowledgments 
458 This study was supported by the EU 7th Framework TB - PANNET and Latvian National 459 Research program VPP-2010-1/9.3 and VPP "BIOMEDICINE”. P.S. was a consultant for 460 Genoscreen.

461

462 


\section{References}

1. Andrés, M., Göhring-Zwacka, E., Fiebig, L., Priwitzer, M., Richter, E., Rüsch-Gerdes, S., Haas, W., Niemann, S., Brodhun, B., 2017. Integration of molecular typing results into tuberculosis surveillance in Germany-A pilot study. PLoS One. 12(11):e0188356. doi: 10.1371/journal.pone.0188356.

2. Bauskenieks, M., Pole, I., Skenders, G., Jansone, I., Broka, L., Nodieva, A., Ozere, I., Kalvisa, A., Ranka, R., Baumanis, V., 2015. Genotypic and phenotypic characteristics of aminoglycoside-resistant Mycobacterium tuberculosis isolates in Latvia. Diagn. Microbiol. Infect. Dis.81(3):177-82. doi: 10.1016/j.diagmicrobio.2014.12.004.

3. Biadglegne, F., Rodloff, A.C., Sack, U., 2015. Review of the prevalence and drug resistance of tuberculosis in prisons: a hidden epidemic. Epidemiol. Infect. 143(5):887900. doi: 10.1017/S095026881400288X.

4. Brudey, K., Gordon, M., Moström, P., Svensson, L., Jonsson, B., Sola, C., Ridell, M., Rastogi, N., 2004. Molecular epidemiology of Mycobacterium tuberculosis in western Sweden. J. Clin. Microbiol. 42(7):3046-51.

5. Chernyaeva, E., Dobrynin, P., Pestova, N., Matveeva, N., Zhemkov, V., Kozlov, A., 2012. Molecular genetic analysis of Mycobacterium tuberculosis strains spread in different patient groups in St. Petersburg, Russia. Eur. J. Clin. Microbiol. Infect. Dis. 31(8):1753-7. doi: 10.1007/s 10096-011-1497-2.

6. Couvin, D., David, A., Zozio, T., Rastogi, N., 2018. Macro-geographical specificities of the prevailing tuberculosis epidemic as seen through SITVIT2, an updated version of the Mycobacterium tuberculosis genotyping database. Infect Genet Evol. S15671348(18)30969-9. doi: 10.1016/j.meegid.2018.12.030. 
7. De Beer, J.L., van Ingen, J., de Vries, G., Erkens, C., Sebek, M., Mulder, A., Sloot, R., van den Brandt, A.M., Enaimi, M., Kremer, K., Supply, P., van Soolingen D., 2013. Comparative study of IS6110 RFLP and VNTR typing of Mycobacterium tuberculosis in the Netherlands, based on a five year nationwide survey. J. Clin. Microbiol. 51(4):11938. doi: 10.1128/JCM.03061-12.

8. Demay, C., Liens, B., Burguière, T., Hill, V., Couvin, D., Millet, J., Mokrousov, I., Sola, C., Zozio, T., Rastogi, N., 2012. SITVITWEB-a publicly available international multimarker database for studying Mycobacterium tuberculosis genetic diversity and molecular epidemiology. Infect. Genet. Evol. 12(4):755-66. doi: 10.1016/j.meegid.2012.02.004.

9. Engström, A., Antonenka, U., Kadyrov, A., Kalmambetova, G., Kranzer, K., Merker, M., Kabirov, O., Parpieva, N., Rajabov, A., Sahalchyk, E., Sayfudtinov, Z., Niemann, S., Hoffmann, H., 2019. Population structure of drug-resistant Mycobacterium tuberculosis in Central Asia. BMC Infect Dis. 29;19(1):908.

\subsection{European Centre for Disease Prevention and Control. Molecular typing for} surveillance of multidrug-resistant tuberculosis in the EU/EEA - January 2016. Stockholm: ECDC; 2016.

9.11. Gori, A., Bandera, A., Marchetti, G., Degli Esposti, A., Catozzi, L., Nardi, G.P., Gazzola, L., Ferrario, G., van Embden, J.D., van Soolingen, D., Moroni, M., Franzetti, F., 2005. Spoligotyping and Mycobacterium tuberculosis. Emerg Infect Dis. 11(8):1242-8. 10.12. Kamerbeek, J., Schouls, L., Kolk, A., van Agterveld, M., van Soolingen, D., et al., 1997. Simultaneous detection and strain differentiation of Mycobacterium tuberculosis for diagnosis and epidemiology. J. Clin. Microbiol. 35: 907-914. 
11.13. Kruuner, A., S. E. Hoffner, H. Sillastu, M. Danilovits, K. Levina, S. B. Svenson,

S. Ghebremichael, T. Koivula, and G. Kallenius. 2001. Spread of drug-resistant

pulmonary tuberculosis in Estonia. J. Clin. Microbiol. 39: 3339-3345.

12.14. Lê, S., Josse, J., Husson, F., 2008. FactoMineR: An R Package for Multivariate Analysis. Journal of Statistical Software. 25(1):1-18.

13.15. Merker, M., Blin, C., Mona, S., Duforet-Frebourg, N., Lecher, S., Willery, E., Blum, M.G., Rüsch-Gerdes, S., Mokrousov, I., Aleksic, E., Allix-Béguec, C., Antierens, A., Augustynowicz-Kopeć, E., Ballif, M., Barletta, F., Beck, H.P., Barry, C.E., Bonnet, M., Borroni, E., Campos-Herrero, I., Cirillo, D., Cox, H., Crowe, S., Crudu, V., Diel, R., Drobniewski, F., Fauville-Dufaux, M., Gagneux, S., Ghebremichael, S., Hanekom, M., Hoffner, S., Jiao, W.W., Kalon, S., Kohl, T.A., Kontsevaya, I., Lillebæk, T., Maeda, S., Nikolayevskyy, V., Rasmussen, M., Rastogi, N., Samper, S., Sanchez-Padilla, E., Savic, B., Shamputa, I.C., Shen, A., Sng, L.H., Stakenas, P., Toit, K., Varaine, F., Vukovic, D., Wahl, C., Warren, R., Supply, P., Niemann, S., Wirth, T., 2015. Evolutionary history and global spread of the Mycobacterium tuberculosis Beijing lineage. Nat. Genet. 47(3):2429. doi: 10.1038/ng.3195.

14.16. Merker, M., Kohl, T.A., Niemann, S., Supply, P., 2017. The Evolution of Strain Typing in the Mycobacterium tuberculosis complex. Adv. Exp. Med. Biol. 1019:43-78. doi: 10.1007/978-3-319-64371-7_3. Assessment of mycobacterial interspersed repetitive unit-QUB markers to further discriminate the Beijing genotype in a population-based study of the genetic diversity of 
Mycobacterium tuberculosis clinical isolates from Okinawa, Ryukyu Islands, Japan. J. Clin. Microbiol. 45(11):3606-15.

16.18. Mokrousov, I., 2012. The quiet and controversial: Ural family of Mycobacterium tuberculosis. Infect. Genet. Evol. 12(4):619-29. doi: 10.1016/j.meegid.2011.09.026.

17.19. Mokrousov, I., Vyazovaya, A., Otten, T., Zhuravlev, V., Pavlova, E.,

Tarashkevich, L., Krishevich, V., Vishnevsky, B., Narvskaya, O., 2012. Mycobacterium tuberculosis population in northwestern Russia: an update from Russian-EU/Latvian border region. PLoS One. 7(7):e41318.

18.20. Mokrousov, I., Vyazovaya, A., Solovieva, N., Sunchalina, T., Markelov, Y.,

Chernyaeva, E., Melnikova, N., Dogonadze, M., Starkova, D., Vasilieva, N., Gerasimova,

19.21. Negin, J., Abimbola, S., Marais, B.J., 2015. Tuberculosis among older adults-time to take notice. Int. J. Infect. Dis. 32():135-7.

A., Kononenko, Y., Zhuravlev, V., Narvskaya, O., 2015. Trends in molecular epidemiology of drug-resistant tuberculosis in Republic of Karelia, Russian Federation. BMC Microbiol. 15:279. doi: 10.1186/s12866-015-0613-3.

20.22. Nikolaevskaya, E., Pavlovska, O., Molina, B., Brännberg, P., Marynova, I., Krylova, K., Ivanitsa, T., Filuk, V., Lacoma, A., Dominguez, J., Rzhepishevska, O., Prat, 548 C., 2016. Spoligotypes of Mycobacterium tuberculosis isolated from tuberculosis patients 549 in Odessa, Ukraine. European Congress of Clinical Microbiology and Infectious Diseases. Amsterdam, Netherlands, 9-12 April, 2016. P0155.

21.23. Nodieva, A., Jansone, I., Broka, L., Pole, I., Skenders, G., Baumanis, V., 2010. Recent nosocomial transmission and genotypes of multidrug-resistant Mycobacterium tuberculosis. Int. J. Tuberc. Lung Dis. 14(4):427-33. 
22.24. Roycroft, E., O'Toole, R.F., Fitzgibbon, M.M., Montgomery, L., O'Meara, M., Downes, P., Jackson, S., O'Donnell, J., Laurenson, I.F., McLaughlin, A.M., Keane, J., Rogers, T.R., 2018. Molecular epidemiology of multi- and extensively-drug-resistant Mycobacterium tuberculosis in Ireland, 2001-2014. J. Infect. 76(1):55-67. doi: 10.1016/j.jinf.2017.10.002.

25. Satta, G., Lipman, M., Smith, G.P., Arnold, C., Kon, O.M., McHugh, T.D., 2018. Mycobacterium tuberculosis and whole-genome sequencing: how close are we to unleashing its full potential? Clin. Microbiol. Infect. 24(6):604-609. doi:

10.1016/j.cmi.2017.10.030.

23.26. Sinkov, V., Ogarkov, O., Mokrousov, I., Bukin, Y., Zhdanova, S., Heysell, S.K., 2019. New epidemic cluster of pre-extensively drug resistant isolates of Mycobacterium

24.27. Smit, P.W., Haanperä, M., Rantala, P., Couvin, D., Lyytikäinen, O., Rastogi, N., 2011. PLoS One. 8(12): e85027.

25.28. Supply, P., C. Allix, S. Lesjean, M. Cardoso-Oelemann, S. Rusch-Gerdes, E. Willery, E. Savine, P. de Haas, H. van Deutekom, S. Roring, P. Bifani, N. Kurepina, B. Kreiswirth, C. Sola, N. Rastogi, V. Vatin, M. C. Gutierrez, M. Fauville, S. Niemann, R. Skuce, K. Kremer, C. Locht, and D. van Soolingen. 2006. Proposal for standardization of optimized mycobacterial interspersed repetitive unit-variable-number tandem repeat typing of Mycobacterium tuberculosis . J. Clin. Microbiol. 44:4498-4510. 
26.29. Supply, P., Mazars, E., Lesjean, S., Vincent, V., Gicquel, B., et al., 2000. Variable human minisatellite-like regions in the Mycobacterium tuberculosis genome. Mol. Microbiol. 36: 762-771.

27.30. Supply, P., Lesjean, S., Savine, E., Kremer, K., van Soolingen, D., Locht, C., 2001. Automated high-throughput genotyping for study of global epidemiology of Mycobacterium tuberculosis based on mycobacterial inter- spersed repetitive units. J. Clin. Microbiol. 39: 3563-3571.

28.31. Toit, K., Altraja, A., Acosta, C.D., Viiklepp, P., Kremer, K., Kummik, T., Danilovitš, M., Van den Bergh, R., Harries, A.D., Supply, P., 2014. A four-year nationwide molecular epidemiological study in Estonia: risk factors for tuberculosis transmission. Public Health Action. 4(Suppl 2):S34-40. doi: 10.5588/pha.14.0045. 29-32. Toungoussova, O. S., P. Sandven, A. O. Mariandyshev, N. I. Nizovtseva, G. Bjune, and D. A. Caugant. 2002. Spread of drug-resistant Mycobacterium tuberculosis strains of the Beijing genotype in the Archangel Oblast, Russia. J. Clin. Microbiol. 40:1930-1937.

30.33. Tracevska, T., Jansone, I., Baumanis, V., Marga, O., Lillebaek, T., 2003. Prevalence of Beijing genotype in Latvian multidrug-resistant Mycobacterium tuberculosis isolates. Int. J. Tuberc. Lung Dis. 7(11):1097-103.

31.34. Vyazovaya, A., Levina, K., Zhuravlev, V., Viiklepp, P., Kütt, M., Mokrousov, I., 2018. Emerging resistant clones of Mycobacterium tuberculosis in a spatiotemporal context. J Antimicrob. Chemother. 73(2):325-331. doi: 10.1093/jac/dkx372. 
32.35. Vyazovaya, A., Mokrousov, I., Zhuravlev, V., Solovieva, N., Otten, T.,

Vishnevsky, B., Narvskaya, O., 2015. Dominance of the Beijing genotype among XDR

Mycobacterium tuberculosis strains in Russia. Int. J. Mycobacteriol. 4 (S1):84-85.

600

33.36. Van Embden, J.D., Cave, M.D., Crawford, J.T., Dale, J.W., Eisenach, K.D., 601

Gicquel, B., Hermans, P., McAdam, R., Shinnick, T.M., Small, P.M., 1993. Strain

602 identification of Mycobacterium tuberculosis by DNA fingerprinting: recommendations 603 for a standardized methodology. J. Clin. Microbiol. 31: 406-409.

604 605

606

607

608

609

610

611

612

613

614

615

616

617

618

van Soolingen, D., Hermans, P.W., de Haas, P.E., Soll, D.R., van Embden, J.D., 1991. Occurrence and stability of insertion sequences in Mycobacterium tuberculosis complex strains: evaluation of an insertion sequence-dependent DNA polymorphism as a tool in the epidemiology of tuberculosis. J. Clin. Microbiol. 29(11):2578-86.

36.39. Weniger, T., Krawczyk, J., Supply, P., Niemann, S., Harmsen, D., 2010. MIRUVNTRplus: a web tool for polyphasic genotyping of Mycobacterium tuberculosis complex bacteria. Nucleic Acids Res. 38(Web Server issue):W326-31. doi: 10.1093/nar/gkq351.

37.40. Zalutskaya, A., Wijkander, M., Jureen, P., Skrahina, A., Hoffner, S., 2013. Multidrug-resistant Myobacterium tuberculosis caused by the Beijing genotype and a specific T1 genotype clone (SIT No. 266) is widely transmitted in Minsk. Int. J. Mycobacteriol. 2(4):194-8. doi: 10.1016/j.ijmyco.2013.08.001. Epub 2013 Sep 6. 
621

622 


\section{Figure captures}

624 Figure 1. Principal component analysis (PCA) of the M. tuberculosis spoligotypes in age groups.

625 PCA map showed remarkable segregation of SIT1 and spoligotypes with a prevalence less than

$6262 \%$ in the population (collectively named as Others).

627

628 Figure 2. Distribution of $M$. tuberculosis lineages in Latvia and neighboring countries. Data

629 were obtained: Latvia, this study; Russia, Mokrousov et al., 2015; Estonia, Vyazovaya et al.,

630 2018; Finland, Smit et al., 2013; Sweden, Brudey et al., 2004; Belarus, Zalutskaya et al., 2013;

631 Ukraine, Nikolaevskaya et al., 2016; Poland, SITWIT database; Germany, SITVIT database;

632 Denmark, SITVIT database.

633 


\section{${ }^{*}$ Author Contributions Section}

Author contributions

Ilva Pole: Investigation, Methodology, Writing- Original draft

Julija Trofimova: Investigation

Inga Norvaisa: Investigation

Philip Supply: Funding acquisition, Writing- Reviewing and Editing

Girts Skenders: Investigation

Anda Nodieva: Investigation

Iveta Ozere: Investigation

Vija Riekstina: Data curation

Viktorija Igumnova: Investigation

Jelena Storozenko: Supervision

Inta Jansone: Conceptualization, Supervision, Investigation

Ludmila Viksna: Funding acquisition, Supervision

Renate Ranka: Conceptualization, Funding acquisition, Supervision, Writing- Reviewing and Editing 